\title{
Chondroitin sulfate tetrasaccharides: synthesis, three- dimensional structure and interaction with midkine
}

\author{
Cristina Solera, ${ }^{[\mathrm{a}]}$ Giuseppe Macchione,${ }^{[\mathrm{a}]}$ Susana Maza, ${ }^{[\mathrm{a}]}$ M. Mar Kayser,${ }^{[\mathrm{a}]}$ Francisco Corzana,${ }^{[\mathrm{b}]}$ José \\ L. de Paz, ${ }^{*[a]}$ Pedro M. Nieto ${ }^{\star[a]}$
}

\begin{abstract}
The biological activity of midkine, a cytokine implicated in neurogenesis and tumorigenesis, is regulated by its binding to glycosaminoglycans (GAGs) such as heparin and chondroitin sulfate (CS). To better understand the molecular recognition of GAG sequences by this growth factor, we have studied here the interactions between synthetic chondroitin sulfate-like tetrasaccharides and midkine using different techniques. First, a synthetic approach for the preparation of CS-like oligosaccharides in the sequence GalNAc-GlcA was developed. A fluorescence polarization competition assay was then employed to analyse the relative binding affinities of the synthetic compounds and revealed that midkine interacts with CS-like tetrasaccharides in the micromolar range. The 3D structure of these tetramers was studied in detail by a combination of NMR experiments and molecular dynamics simulations. Saturation transfer difference (STD) NMR experiments indicate that the CS tetrasaccharides bind to midkine in an extended conformation, with similar saturation effects along the entire sugar chain. These results are compatible with docking studies suggesting an interaction of the tetrasaccharide with midkine in a folded structure. Overall, our study gives valuable information on the interaction between midkine and well-defined, chemically synthesized CS oligosaccharides and these data can be useful for the design of more active compounds that modulate the biological function of this protein.
\end{abstract}

\section{Introduction}

Chondroitin sulfate (CS) is a linear sulfated polysaccharide that is involved in important biological processes such as central nervous system development and malaria infection. ${ }^{[1]} \mathrm{CS}$ is formed by the repetition of disaccharide units of D-glucuronic acid (GlcA) and $N$-acetyl-D-galactosamine (GalNAc), following the sequence GlcA- $\beta(1 \rightarrow 3)$-GalNAc- $\beta(1 \rightarrow 4)$, that may contain sulfate groups at different positions of the chain. CS has a high level of structural diversity due to the presence of different sulfate group distributions. The participation of CS in a wide variety of biological processes involves its interaction with

[a] C. Solera, Dr. G. Macchione, Dr. S. Maza, M. M. Kayser, Dr. J. L. de Paz, Dr. P. M. Nieto

Glycosystems Laboratory

Instituto de Investigaciones Químicas (IIQ), cicCartuja, CSIC and Universidad de Sevilla

Americo Vespucio, 49, 41092 Sevilla, Spain

E-mail: pedro.nieto@iiq.csic.es; ilpaz@iiq.csic.es

[b] Dr. F. Corzana

Departamento de Química, Centro de Investigación en Síntesis

Química

Universidad de La Rioja

Madre de Dios, 51, 26006 Logroño, Spain

Supporting information for this article is given via a link at the end of the document. certain proteins, and these interactions require a specific arrangement of sulfate groups ${ }^{[2]} \mathrm{CS}$ oligosaccharide sequences, with particular sulfation motifs, are therefore responsible for protein recognition and subsequent activity. For instance, CS-E, with the disulfated sequence GlcA-GalNAc(4,6-di-OSO ${ }_{3}$ ), binds to several neurotrophins, selectins and chemokines. ${ }^{[3]}$

Midkine is a heparin-binding growth factor that promotes development, migration and survival of several types of cells. ${ }^{[4]}$ For example, midkine participates in neuronal adhesion, growth and migration, playing an important role in the development of the central nervous system. Moreover, high expression of midkine is often observed in different classes of cancer cells. This protein is also involved in inflammatory diseases. For all these reasons, midkine is a promising molecule for drug development. Midkine inhibitors ${ }^{[5]}$ may be of great value in the treatment of malignant tumors and multiple sclerosis. On the other hand, survival-promoting activity of midkine has the potential to treat and prevent neuronal degeneration processes such as Alzheimer's disease.

Heparin and chondroitin sulfate, in particular CS-E, are known to bind strongly to midkine. The dissociation constant values for both interactions are similar, falling in the nanomolar range. ${ }^{[6]}$ It is now well accepted that both polysaccharides, heparin and CS, are essential for the activity of this growth factor. As already mentioned, the interaction between CS and midkine is sensitive to the sulfation pattern and it has been demonstrated that a specific arrangement of sulfate groups, the 4,6-di-O-sulfated CS$\mathrm{E}$ motif, is required for binding. ${ }^{[2]}$ However, a lot of questions remain unsolved and novel studies on the interaction between CS sequences and midkine are strongly demanded in order to discover new structure activity relationships and deepen the understanding of these molecular recognition events. For instance, it is unknown if the introduction of an additional sulfate group or the substitution of a glucuronic acid by an iduronic acid moiety in CS-E sequences, giving rise to different sulfation patterns and hybrid CS-dermatan sulfate chains respectively, can substantially affect the binding to midkine. In this context, homogeneous and structurally defined synthetic CS oligosaccharides can be very useful to study these interactions at the molecular level. Despite the recent advances in CS oligosaccharide synthesis, ${ }^{[7]}$ the development of new synthetic approaches for this type of molecules is still of great interest. Importantly, chemical synthesis can also afford CS analogues and mimetics, ${ }^{[8]}$ with non-natural sequences, that may display improved biological activities and novel therapeutic applications.

In this manuscript, we have employed synthetic CS-like oligosaccharides to study their interactions with midkine. First of all, we have carried out the total synthesis of a CS-E tetrasaccharide. This derivative was incorporated in our collection of oligosaccharide structures that includes CS 
tetramers with an iduronic acid unit at the non-reducing end instead of a GlcA, and sulfate group distributions corresponding to the CS-T subtype, characterised by the trisulfated disaccharide unit $\mathrm{GlcA}\left(2-\mathrm{OSO}_{3}\right)$-GalNAc(4,6-di-OSO $\left.{ }_{3}\right){ }^{\left[{ }^{9]}\right.}$ The interaction between midkine and the library of synthetic oligosaccharides was analysed using fluorescence polarization assays. We then performed a detailed analysis of the 3D structure of the CS tetrasaccharides by using a combination of NMR experiments and molecular dynamic simulations as a previous step for the subsequent STD NMR experiments and docking studies of the CS-midkine complexes. ${ }^{[10]}$

\section{Results and Discussion}

\section{Synthesis of a CS tetrasaccharide with the sequence} GaINAc-GIcA

We have previously developed a synthetic strategy for the preparation of CS-like tetrasaccharides in the GlcA-GaINAc sequence (see below). ${ }^{[11]}$ This approach was based on the use of $\mathrm{N}$-trifluoroacetyl ( $\mathrm{N}$-TFA) protected galactosamine building blocks. ${ }^{[12]}$ We showed that this type of GalNAc units were highly convenient for the synthesis of CS oligomers since the $N$-TFA protecting group ensures the selective formation of the required 1,2-trans glycosidic bond and can be easily removed at the end of the route to install the naturally occurring 2 -acetamido moiety. Besides the length and the sulfation pattern, the sequence (GlcA-GalNAc or GalNAc-GlcA) is another important feature to be considered when studying the interactions between CS oligosaccharides and proteins. Here, we present the total synthesis of CS tetrasaccharide $\mathbf{1 5}$ with the alternative sequence GalNAc-GlcA. For this purpose, we have followed the retrosynthetic analysis shown in Scheme 1. The tetramer structure was obtained by a $2+2$ coupling of disaccharide units, prepared from key compound 7 . This derivative contains a cyclic silylene group at positions 4 and 6 of the galactosamine unit that allows their selective sulfation in order to generate CS sequences with the biologically relevant $\mathrm{E}$ sulfation motif. Disaccharide 7 was synthesized from monosaccharides $\mathbf{3}$ and $4^{[12]}$ that were obtained on a gram-scale from commercially available galactosamine hydrochloride and 1,2;5,6-di-Oisopropylidene- $\alpha$-D-glucofuranose, respectively.

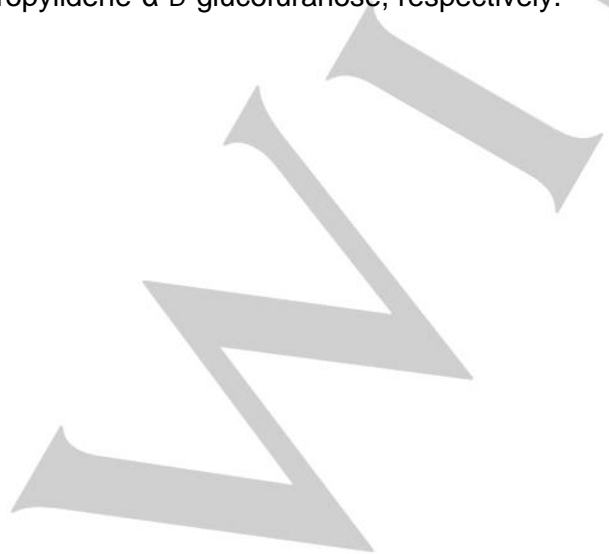

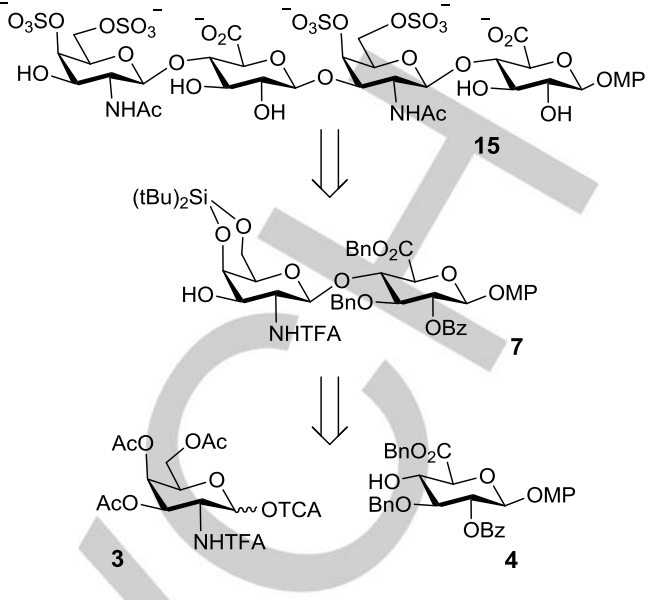

Scheme 1. Retrosynthetic analysis for the preparation of CS tetrasaccharide 15.

The anomeric acetate group of compound $\mathbf{1}^{[12]}$ was selectively removed by treatment with hydrazine monohydrate (Scheme 2). Compound $\mathbf{2}$ was transformed into glycosyl trichloroacetimidate 3 using trichloroacetonitrile and catalytic DBU. Glycosylation reaction between donor 3 and glucuronic acid acceptor 4 afforded the desired disaccharide 5 in excellent $85 \%$ yield. Next, the protecting groups of the GalNAc moiety were rearranged to obtain key building block 7 . The protecting group distribution of this derivative allows the elongation of the oligosaccharide chain by glycosylation of the $3-\mathrm{OH}$ group. The selective hydrolysis of the three acetates of compound 5 in the presence of benzoate and benzyloxicarbonyl groups was a challenging step. Triol 6 was obtained in an acceptable yield by using $p$-toluenesulfonic acid (3 equiv.) in a $\mathrm{CH}_{2} \mathrm{Cl}_{2} / \mathrm{MeOH}$ mixture. ${ }^{[13]}$ Treatment with ditert-butylsilyl bistriflate in pyridine gave 7 in excellent yield. As mentioned before, the orthogonal silylene group enables the selective introduction of sulfates at the end of the synthesis. Moreover, this cyclic silyl group has several advantages over 4,6-O-benzylidene acetals, such as better solubility in most organic solvents and higher stability under acidic glycosylation conditions. However, it is important to note that the silylene group must be introduced at the disaccharide stage, after the formation of the GalNAc-GlcA bond, since the presence of a 4,6di-tert-butylsilylene group in galactosamine (and galactose) donors leads to the predominant formation of the a glycoside, even in the presence of 2-participating groups. ${ }^{[14]}$ 

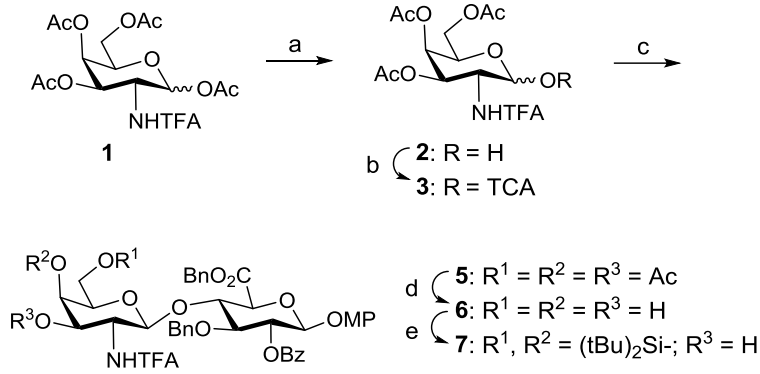

Scheme 2. Reagents and conditions: a) $\mathrm{NH}_{2} \mathrm{NH}_{2} \cdot \mathrm{H}_{2} \mathrm{O}$, Py/AcOH, $\mathrm{CH}_{2} \mathrm{Cl}_{2}$, $73 \%$; b) $\mathrm{Cl}_{3} \mathrm{CCN}$, DBU, $\mathrm{CH}_{2} \mathrm{Cl}_{2}, 72 \%$; c) 4, TMSOTf, $\mathrm{CH}_{2} \mathrm{Cl}_{2}, 0^{\circ} \mathrm{C}, 85 \%$; d) $p$ $\mathrm{TsOH}, \mathrm{CH}_{2} \mathrm{Cl}_{2} / \mathrm{MeOH}, 52 \%$; e) $t \mathrm{Bu} \mathrm{Si}_{2}(\mathrm{OTf})_{2}, \mathrm{Py}, 84 \%$.

Disaccharide 7 (Scheme 3) was converted into trichloroacetimidate $\mathbf{1 0}$ by levulinoylation $(\rightarrow \mathbf{8})$, followed by removal of the 4-methoxyphenyl group $(\rightarrow 9)$ and treatment with trichloroacetonitrile and $\mathrm{K}_{2} \mathrm{CO}_{3}(\rightarrow \mathbf{1 0})$. Thus, disaccharide 5 can be transformed, on a gram-scale, in both glycosyl donor (10) and acceptor (7), ready for $2+2$ coupling reactions and assembly of growing oligosaccharide chains. Tetrasaccharide 11 was prepared by condensation of $\mathbf{7}$ and $\mathbf{1 0}$. Silylene groups were then selectively removed by treatment with $(\mathrm{HF})_{n} \cdot$ Py complex. Tetraol 12 was sulfated under microwave irradiation ${ }^{[15]}$ to afford 13 in excellent yield. The introduction of the sulfate groups at positions 4 and 6 of the GalNAc units, corresponding to the $E$ sulfation pattern of chondroitin sulfate, was confirmed by ${ }^{1} \mathrm{H}$ and ${ }^{13} \mathrm{C}$ NMR spectroscopic data, which showed typical downfield shifts for these positions. Basic hydrolysis of ester and amide groups followed by selective $\mathrm{N}$-acetylation gave water-soluble dibenzylated tetrasaccharide 14. Finally, hydrogenolysis afforded fully deprotected tetramer $\mathbf{1 5}$ in good yield. The structure of this compound was confirmed by the analysis of the ${ }^{1} \mathrm{H}$ and ${ }^{13} \mathrm{C}$ NMR data that are in full agreement with those published for similar oligosaccharides. Both 15 and its dibenzylated precursor $\mathbf{1 4}$ were included in our library of synthetic oligosaccharides for interaction studies with midkine.

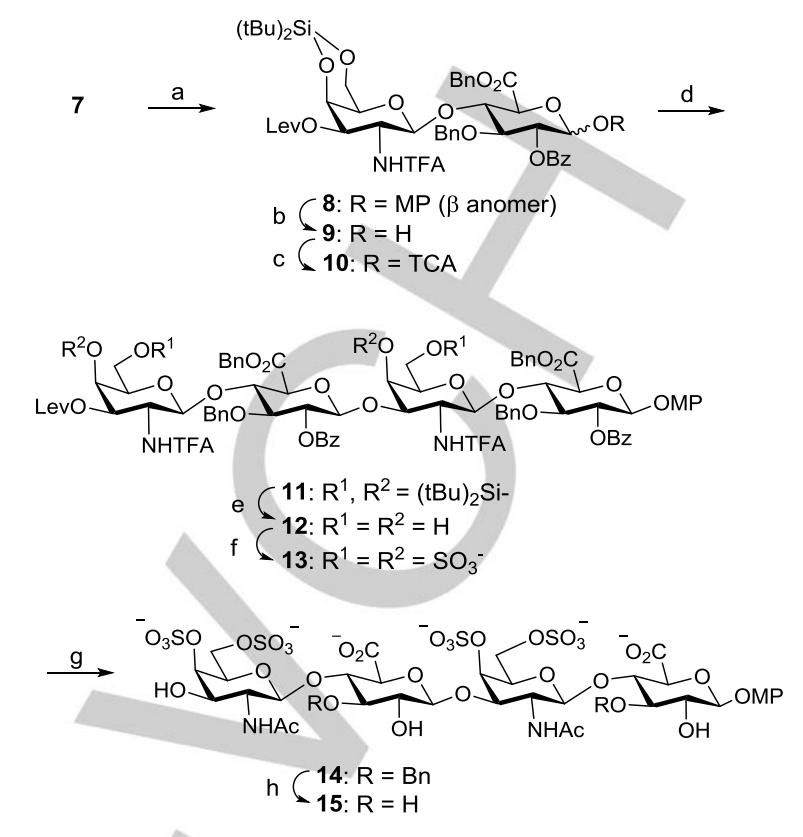

Scheme 3. Reagents and conditions: a) $\mathrm{Lev}_{2} \mathrm{O}, \mathrm{CH}_{2} \mathrm{Cl}_{2}$, DMAP, $87 \%$; b) $\mathrm{CAN}$ $\mathrm{CH}_{2} \mathrm{Cl}_{2} / \mathrm{CH}_{3} \mathrm{CN} / \mathrm{H}_{2} \mathrm{O}$, 82\%; c) $\mathrm{Cl}_{3} \mathrm{CCN}, \mathrm{K}_{2} \mathrm{CO}_{3}, \mathrm{CH}_{2} \mathrm{Cl}_{2}$, quantitative; d) 7 TMSOTf, $\mathrm{CH}_{2} \mathrm{Cl}_{2}, 0^{\circ} \mathrm{C}, 54 \%$; e) $(\mathrm{HF})_{n} \cdot \mathrm{Py}$, THF, $0^{\circ} \mathrm{C}$, quantitative; f) $\mathrm{SO}_{3} \cdot \mathrm{Me}_{3} \mathrm{~N}$ DMF, $100^{\circ} \mathrm{C}, \mathrm{MW}, 30 \mathrm{~min}$, quantitative; g) $\mathrm{LiOH}, \mathrm{H}_{2} \mathrm{O}_{2}, \mathrm{THF} ; \mathrm{NaOH}$, $\mathrm{MeOH} / \mathrm{H}_{2} \mathrm{O} ; \mathrm{Ac}_{2} \mathrm{O}, \mathrm{MeOH}, \mathrm{Et}_{3} \mathrm{~N}, 62 \%$; h) $\mathrm{H}_{2}, \mathrm{Pd}(\mathrm{OH})_{2} / \mathrm{C}, \mathrm{H}_{2} \mathrm{O} / \mathrm{MeOH}, 92 \%$.

\section{Interaction of CS tetrasaccharides with midkine by fluorescence polarization measurements}

Next, we studied the interactions between midkine and our collection of chemically synthesized heparin ${ }^{[16]}$ and CS oligosaccharides (Figure 1)..$^{[11-12]}$ The library comprises CS-like di- and tetrasaccharides, differing in the sulfation pattern and sequence, including compounds 14 and 15 . Tetrasaccharides 16 and 17 have the alternative GlcA-GalNAc sequence and contain seven sulfate groups, a sulfation pattern corresponding to CS$\mathrm{T}^{[\mathrm{9a}]}$ with an additional sulfate group at position 4 of the nonreducing end. The analysis of the binding properties of these CS analogs, only accessible through chemical synthesis, is highly interesting because it has been recently reported that oligosaccharides with novel "synthetic" sulfation profiles display relevant biological properties. ${ }^{[17]}$ Compounds 18, 19, 20 and 21 present an L-iduronic acid (IdoA) unit at the non-reducing end of the chain, instead of a GlcA. The presence of IdoA moieties in the CS chains gives rise to the so-called hybrid chondroitin/dermatan sulfate (CS/DS) that plays a crucial role in the central nervous system development. ${ }^{[9 a, 18]}$ Tetrasaccharides 18 and 19 are related to the CS-T sulfate distribution while the sulfation profile of $\mathbf{2 0}$ and 21 corresponds to the chondroitin sulfate $E$ type. Synthetic heparin-like oligosaccharides $\mathbf{2 4 - 2 7 ^ { [ 1 6 ] }}$ were also included in the study for comparison purposes since midkine recognizes heparin and CS-E polysaccharidic chains with similar affinities. 


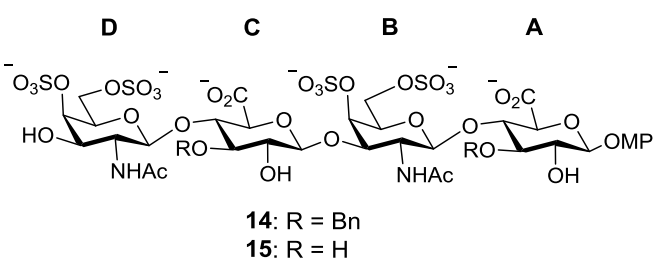

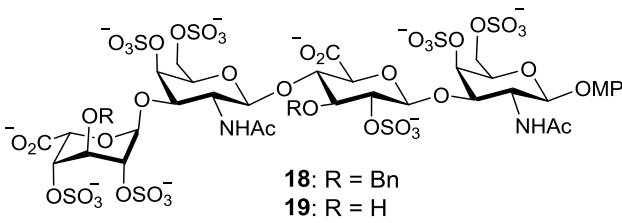

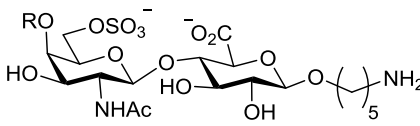

$$
\text { 22: } \mathrm{R}=\mathrm{H}
$$$$
\text { 23: } \mathrm{R}=\mathrm{SO}_{3}
$$

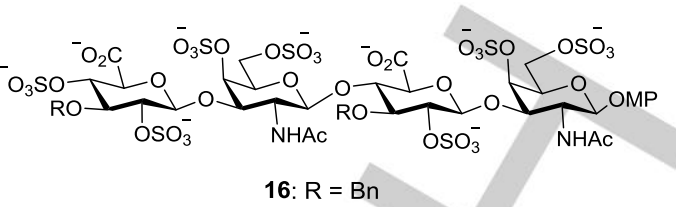

17: $\mathrm{R}=\mathrm{H}$

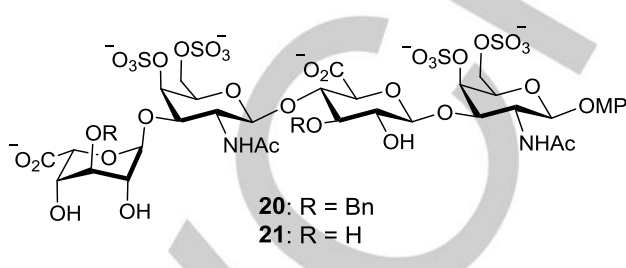

$$
\text { 24: } \mathrm{n}=0 ; \mathrm{R}=\mathrm{H} ; \mathbf{2 5}: \mathrm{n}=1 ; \mathrm{R}=\mathrm{H}
$$

26: $\mathrm{n}=2 ; \mathrm{R}=\mathrm{H} ; 2 \mathrm{27}: \mathrm{n}=2 ; \mathrm{R}=\mathrm{SO}_{3}{ }^{-}$

Figure 1. Structures of the synthetic oligosaccharides employed in the interaction studies with midkine. Throughout the paper, unit $A$ refers to the reducing end monosaccharide.

In order to study the binding between these synthetic sugars and midkine, we have employed a competition fluorescence polarization assay, previously developed in our lab. ${ }^{[12]}$ This technique is ideal for high throughput screening, requiring very little amount of samples for the fast analysis of biomolecular interactions in solution. ${ }^{[19]}$ The relative binding affinities of the oligosaccharides were measured as their abilities to inhibit the interaction between a protein, midkine, and a fluorescent heparin probe. If an oligosaccharide binds to midkine, the fluorescent probe will be displaced from the protein, producing a decrease in the fluorescence polarization $(P)$ value. These measurements were performed in 384-well microplates by using a standard fluorescence reader.

The correct design of a competition fluorescence polarization experiment requires the previous analysis of the fluorescence probe/protein interaction. ${ }^{[19 a, c]}$ Therefore, we first measured the direct binding of the probe (a heparin hexasaccharide with a covalently linked fluorescein moiety ${ }^{[12]}$ ) to midkine (Figure 2). The polarizations of samples containing a fixed concentration of probe and increasing concentrations of midkine were recorded. The obtained binding curve was fitted to the equation for a onesite binding model and the value of the dissociation constant $\left(\mathrm{K}_{\mathrm{D}}\right), 44 \pm 5 \mathrm{nM}$, was determined.

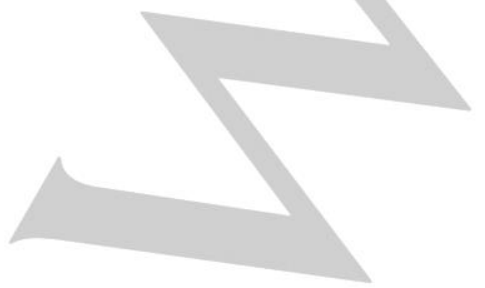

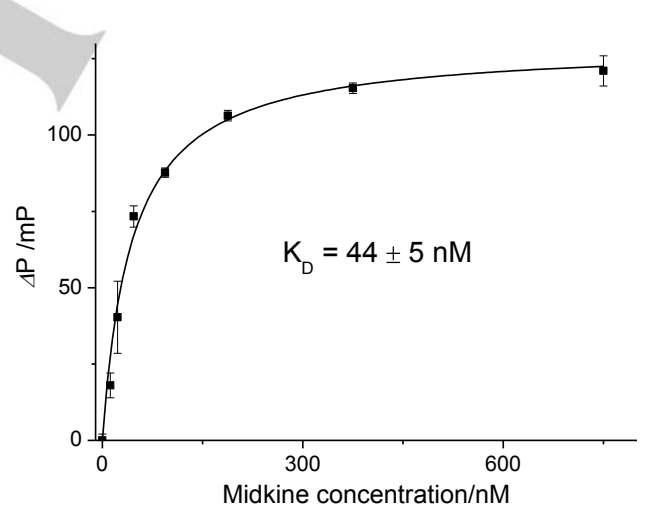

Figure 2. Direct binding assay for the interaction of midkine with the fluorescent probe. We recorded the polarizations $(P)$ of wells containing a fixed concentration of probe $(10 \mathrm{nM})$ and increasing concentrations of midkine (ranging from $12 \mathrm{nM}$ to $750 \mathrm{nM}$ ). The $\Delta \mathrm{P}$ values were obtained by subtracting the background polarization of probe solution from the polarization values of sample solutions (see experimental part). $\Delta \mathrm{P}$ was plotted against midkine concentration and the binding curve was fitted to the equation for a one-site binding model. The plotted data are the averages of three replicate wells and the error bars represent the standard deviations.

After establishing conditions for observation of the binding between midkine and the fluorescent probe, we carried out the competition assay to screen the relative binding affinities of our library of synthetic oligosaccharides. For this purpose, we recorded the polarization of samples containing fixed concentrations of midkine $(47 \mathrm{nM})$ and fluorescent probe (10 $\mathrm{nM}$ ) in the presence of the different synthetic sugars. In competition fluorescence polarization experiments, the ratio 
between the protein concentration and the $K_{D}$ value for the probe/protein interaction should be at least 1 . Thus, we carried out our competition assays using a midkine concentration of 47 $\mathrm{nM}$. Regarding the inhibitor concentration, we performed an initial screening at $25 \mu \mathrm{M}$ (Figure 3). Two control samples were also included in the experiment: the first one contained only the fluorescent probe and the second one contained midkine and probe without inhibitor. The inhibition percentages shown in Figure 3 were calculated by using the polarization of these two control samples as the reference values for $100 \%$ and $0 \%$ inhibition, respectively.

Oversulfated tetrasaccharides 16, 17, 18 and 19 showed high inhibition of the midkine/probe interaction, indicating that these molecules strongly bound to the protein. On the contrary, compounds 14-15 and 20-21 displayed only low to moderate activity, suggesting that the number of sulfate groups is an important structural feature to be considered in midkineoligosaccharide binding, as expected for molecular recognition processes mainly governed by electrostatic interactions. However, our results also indicate that other factors, such as the monosaccharide sequence and the presence of hydrophobic benzyl protecting groups, can also influence on the binding. In fact, comparing the activities of CS-like tetrasaccharides with four sulfate groups, we observed that $\mathbf{1 4}$ significantly showed the highest inhibition values.

The interaction between CS-E tetrasaccharides and midkine has been demonstrated by microarray ${ }^{[2]}$ and surface plasmon resonance ${ }^{[20]}$ experiments in which the sugars were immobilized on appropriately functionalized glass slides and gold chips, respectively. Tetrasaccharide $\mathbf{1 5}$ displays the same sulfation motif than the compounds employed in those experiments and we therefore expected its binding to midkine. However, 15 did not exhibit significant activity at $25 \mu \mathrm{M}$ concentration. We then decided to perform a second screening at a higher inhibitor concentration, $250 \mu \mathrm{M}$ (Figure S1, Supporting information). In this experiment, 15 bound to midkine, giving around $50 \%$ inhibition. A $K_{D}$ value of $2.6 \mathrm{nM}$ has been reported for the interaction between midkine and a CS-E tetrasaccharide using surface plasmon resonance. ${ }^{[20]}$ Our results point out a much weaker interaction between $\mathbf{1 5}$ and midkine, in the micromolar range. This discrepancy can be partially explained by the different nature of the binding experiment. Fluorescence polarization measurements evaluate the interactions in solution while SPR experiments analyse the binding that occurs at a surface on which the carbohydrate ligand was immobilized.

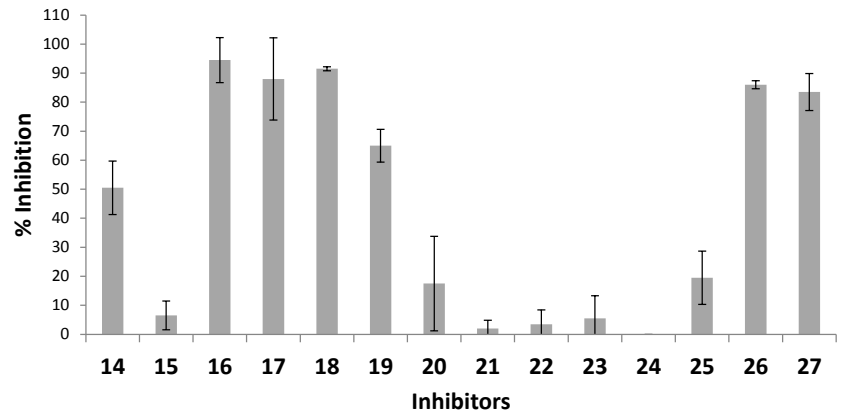

Figure 3. Screening assay of the synthetic oligosaccharides at $25 \mu \mathrm{M}$ concentration. The inhibition percentages were calculated by using the polarization of reference samples for $100 \%$ and $0 \%$ inhibition (see main text and experimental section). The data displayed are the average of two independent experiments, each one in three replicates, with error bars showing the standard deviations for these measurements.

On the other hand, Figure 3 also shows that heparin di- and tetrasaccharide did not interact with midkine at $25 \mu \mathrm{M}$ concentration, while heparin hexasaccharides 26 and 27 displayed more than $75 \%$ inhibition. Interestingly, the large difference in relative binding affinities between tetra- 25 and hexamers 26-27 suggests that a minimum length is required for the strong binding of heparin oligosaccharides to midkine.

CS-like tetrasaccharides that displayed more than $60 \%$ midkine inhibition were considered for detailed $\mathrm{IC}_{50}$ quantification. For this purpose, we measured the fluorescence polarization of wells containing a fixed concentration of midkine and probe and increasing concentrations of inhibitor (Figure S2). Polarization was then plotted against the logarithm of inhibitor concentration and the curve was fitted to the formula corresponding to a onesite competitive interaction. Table 1 shows the calculated $I C_{50}$ values for compounds 16-19. The differences between these values (from $2.5 \mu \mathrm{M}$ for $\mathbf{1 8}$ to $10.6 \mu \mathrm{M}$ for 17 ) indicate that the presence of both an IdoA unit at the non-reducing end and benzyl groups at positions 3 of the uronic acid moieties slightly modify the relative binding affinities to midkine. Besides the number and position of sulfate groups, these structural modifications can also modulate the interactions with midkine. Finally, we also determined the $\mathrm{IC}_{50}$ value for $\mathbf{2 7}$ that proved to be the most potent inhibitor.

Table 1. $I C_{50}$ values of synthetic oligosaccharides.

\begin{tabular}{cccccc}
\hline Compound & $\mathbf{1 6}$ & $\mathbf{1 7}$ & $\mathbf{1 8}$ & $\mathbf{1 9}$ & $\mathbf{2 7}$ \\
\hline $\mathrm{IC}_{50}(\mu \mathrm{M})$ & 5.3 & 10.6 & 2.5 & 8.0 & 1.1 \\
\hline
\end{tabular}

\section{Structural analysis of tetrasaccharides}

We have also performed a solution structural study for compounds 15, 17, 19 and 21 to be used in further structureactivity relationships. These tetrasaccharides have been studied mainly by homonuclear NMR obtaining structural restrains: torsional angles from coupling constants and distances from 
NOE quantification. These experimental data were further compared with the results obtained from molecular dynamics simulations, both with and without time averaged experimental restrains. All the tetrasaccharides have temperature and base frequency dependent NMR spectra, suggesting the presence of an important conformational equilibrium. The NMR experiments for spectral assignment, as presented in the experimental part, were recorded at $323 \mathrm{~K}$ at $400 \mathrm{MHz}$ as all the signals were detected with a narrower shape. However, the NMR experiments for 3D structural calculations were registered between 278 and $288 \mathrm{~K}$ in order to increase the population of the most stable conformation, to avoid potential interferences from high-energy conformations and to ensure a more favourable NOE growing regime.
We have obtained the interprotonic experimental distances from 1D and 2D NOESY experiments at variable mixing times from the cross-peaks initial growing rates at low temperatures, between 278 and $283 \mathrm{~K}$, using the Isolated Spin Pair Approximation (ISPA), ${ }^{[21]}$ see experimental part. The experimental results are consistent with a general extended conformation for tetrasaccharides with the glycosidic linkages in a syn- $\psi$ type arrangement, detected by NOE short distances between protons at both flanks of the linkages (table 2). Coupling constants were also extracted from the spectra and mostly correspond to the canonical expected conformations for all the monosaccharide rings except for unit $D$ of compound $\mathbf{2 1}$ that has different values than expected for a single chair conformation (tables S1-S4, see Supporting Information).

Table 2. NMR interprotonic distances.

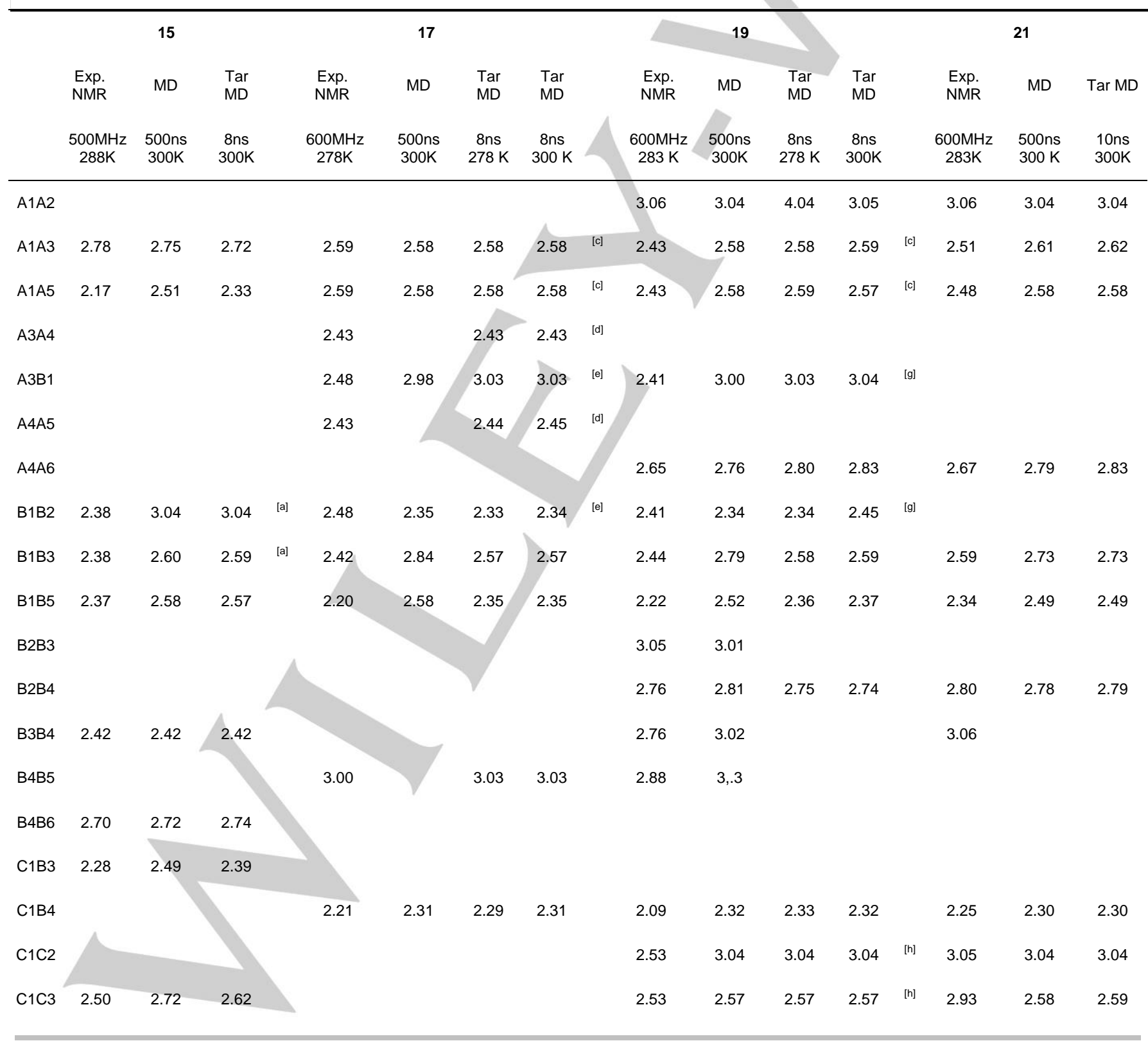




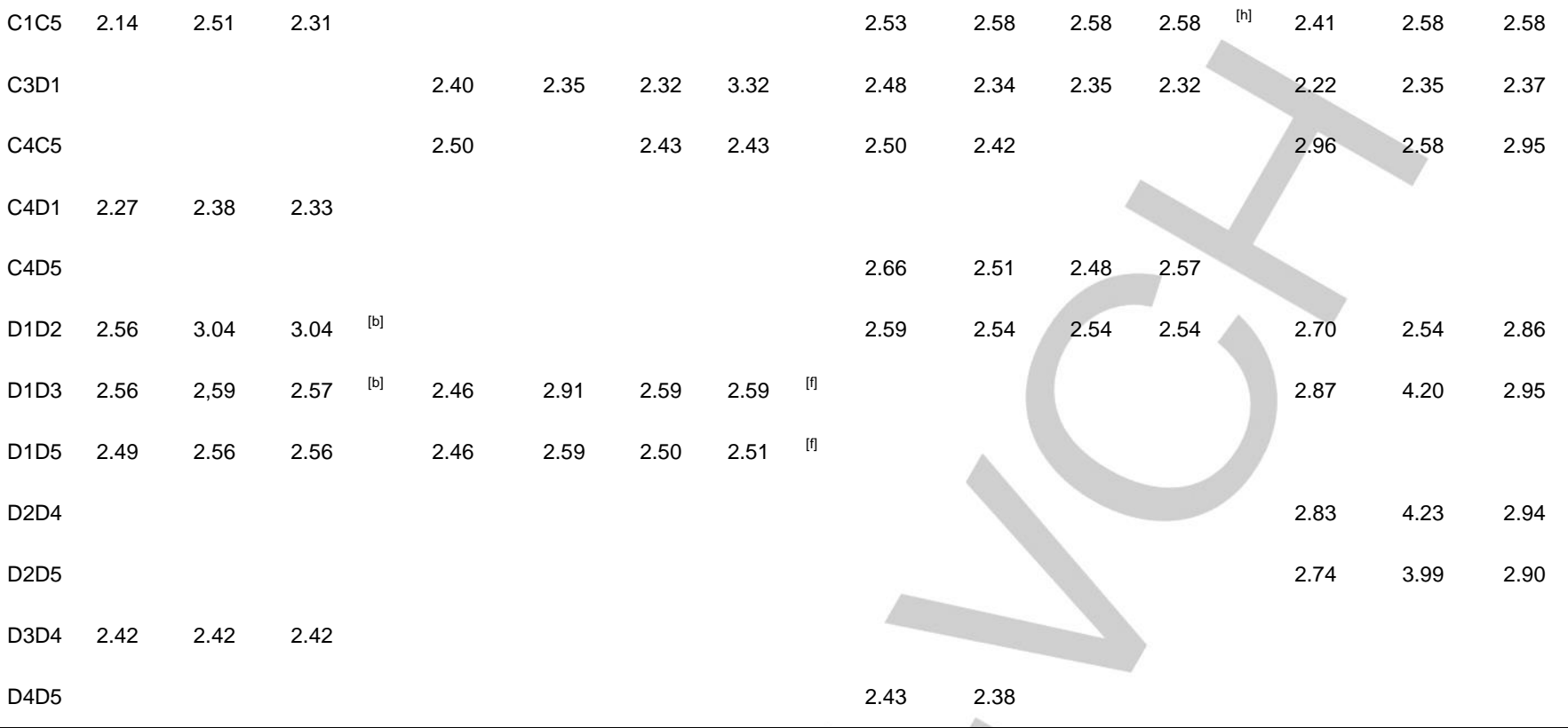

[a] Overlapping B1B2-B1B3. [b] Overlapping D1D2-D1D3. [c] Overlapping A1A3-A1A5. [d] Overlapping A4A3-A4A5. [e] Overlapping A3B1-B1B2. [f] Overlapping D1D3-D1D5. [g] Overlapping A3B1-B1B2. [h] Overlapping C1C2-C1C3-C1C5.

Next, we have performed Molecular Dynamics (MD) studies on the four compounds to have further structural information to be applied in the conformational analysis. We run MD free simulations on 17 using Glycam06 as previously reported for heparin like oligosaccharides. ${ }^{[22]}$ We did process the structures to extract geometrical values to compare with the experimental data from NMR and we have found that they agreed consistently. The coupling constants were calculated as the weighted average over the length of the whole simulation for each frame, considering the modified Altona equation for the calculated instant values. ${ }^{[23]}$ Only residue $\mathrm{D}$, and in less extent $\mathrm{B}$, presented some conformational flexibility that was reflected in the calculated coupling constant values that were deviated from the experimental ones (see Supporting Information, table S2). Interprotonic interesidue distances, however, were consistent with the NOE-based experimental ones (table 2). Then we decide to use time averaged distance restrained MD (tar-MD) ${ }^{[24]}$ using as experimental restrains the distances between the protons $\mathrm{H} 1$ to $\mathrm{H} 3$ and $\mathrm{H} 1$ to $\mathrm{H} 5$ of the rings $\mathrm{B}$ and $\mathrm{D} \cdot{ }^{[23]}$ In this case we obtained monoconformational behaviour for all the rings included D (Figures 4 and 5). The coupling constant calculated from the MD-tar trajectories are now in agreement with the experimental ones that account for a stable ${ }^{4} C_{1}$ conformation of the ring $D$, at least in a $98.2 \%$ of the trajectory when the simulation was performed at $300 \mathrm{~K}$. When the same MD-tar was run at $278 \mathrm{~K}$ no evidences of conformational changes were detected at all (Table 2). Tetrasacharide 15, with the opposite sequence as 17 , also has monoconformational behaviour, with all the rings in ${ }^{4} C_{1}$ conformation as correspond to the native unsulfated residues (Figure 5).
We then performed a similar study on 19 and 21, both containing an IdoA unit at the non-reducing end. It is well established that iduronic acid rings usually present a typical conformational equilibrium between the chairs ${ }^{1} C_{4}$ and ${ }^{4} C_{1}$ and the skew-boat ${ }^{2} S_{0}$. However, the free MD of 19 showed a single conformational behaviour of the monosaccharide residues, even when the MD was launched from a ${ }^{2} S_{0}$ skew-boat conformation for unit $\mathrm{D}$ that quickly switched to chair ${ }^{1} C_{4}$. When the time averaged restrictions were included, this behaviour was confirmed. Coupling constant analysis of the ring $D$ also agrees with monoconformational behaviour of this ring with small coupling constant values in agreement with the experimental ones. The experimental distances are also in agreement with the results of the molecular dynamic simulations, both with and without restrictions, in which the ring $\mathrm{D}$ was in ${ }^{1} \mathrm{C}_{4}$ conformation (Figure 5).

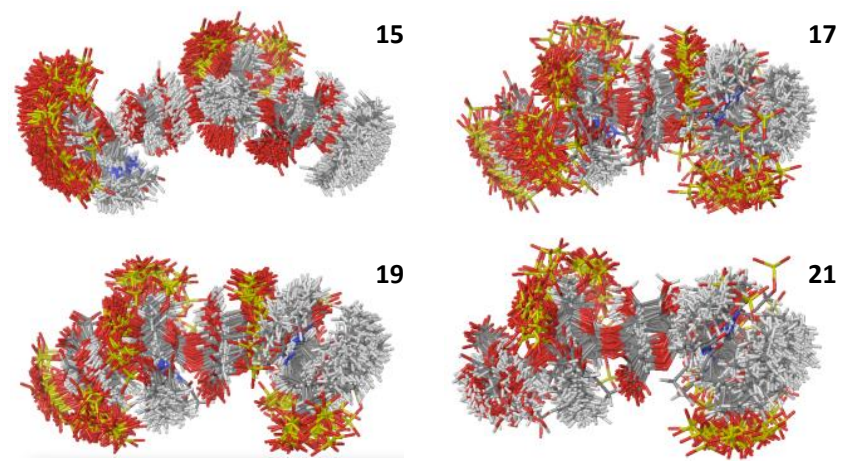

Figure 4. Superimposition of the structures of tetrasaccharides 15, 17, 19 and 21 along 8 ns MD-tar simulations. 

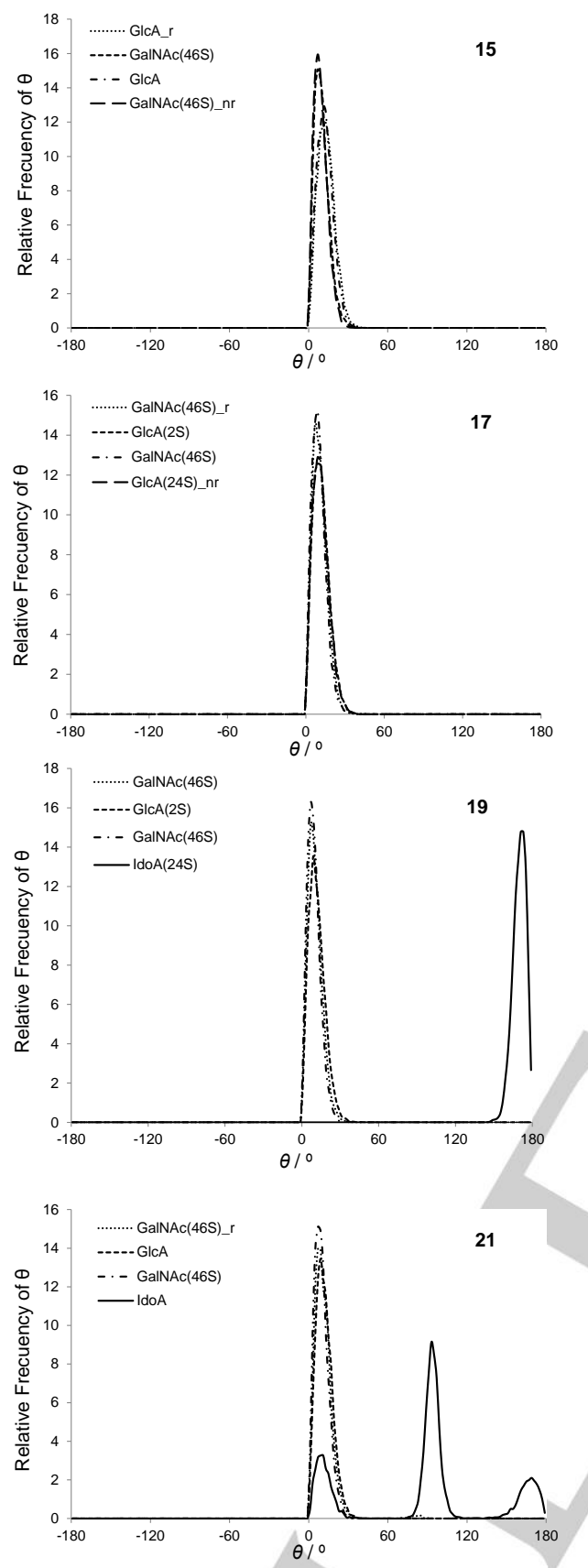

Figure 5. Representation of puckering coordinates $(\theta)$ of tetrasaccharides 15, 17, 19 and 21. The puckering coordinates of 21 show the presence of equilibrium between conformers in the non-reducing IdoA residue.

In the case of $\mathbf{2 1}$, the non-reducing end residue, an iduronate ring with three free hydroxyls, presents an intense conformational equilibrium. This can be deduced from the coupling constants that have intermediate values that do not correspond to a single conformation. The $\beta_{H H}$ experimental coupling values are coherent with a fast equilibrium between at least three conformations, ${ }^{1} C_{4},{ }^{4} C_{1}$, and ${ }^{2} S_{O}$. Unrestrained MD simulations did not reproduce this equilibrium and the ${ }^{1} C_{4}$ conformation was stable along the trajectory. Only scarce transitions to the Cremer-Pople $\theta=90^{\circ}$ were detected. However, when the experimental distance between $\mathrm{H} 2$ and $\mathrm{H} 5(2.74 \AA)$ was introduced as time averaged restrain on ring $D$, the results satisfied the experimental coupling constant data (see Supporting Information, table S4). We evaluated the results from the 10 ns tar-MD considering the canonical conformations ${ }^{25} B$ and $B^{30}$ included into the same conformational group that ${ }^{2} S_{O}$. It must be emphasised that ${ }^{25} B$ and $B^{30}$ conformations are the closest neighbours of the ${ }^{2} S_{O}$ in the Cremer-Pople sphere pseudorotational equator, $\theta=90^{\circ}$. Then, considering the group ${ }^{2} S_{O}$ as the ensemble of ${ }^{2} S_{O},{ }^{25} B$ and $B^{30}$, an $88 \%$ of the total population of the trajectory is represented and varies between ${ }^{1} C_{4},{ }^{4} C_{1}$, and ${ }^{2} S_{O}$ (Figure 5). In addition, the weighting averaged theoretical coupling constant values also agreed with the experimental ones.

All tetrasaccharides show an extended structure (figures 4 and 6 ), with $\Phi / \Psi$ maps corresponding to a syn- $\Phi / \psi$ disposition (see Supporting Information, figures S3-S10). When time averaged restrains were applied, the space visited during the MD-tar was reduced, fitting better with the experimental values. In the case of the tetrasaccharide with the opposed sequence, 15, this effect was even more accused, as its free MD is compatible with a more flexible compound (see Supporting Information, figures S3 and S4).

Interestingly enough, the structures of the four tetrasaccharides can be superimposed assuming the sequence inversion or shift in 15 with respect to the rest. Independently on the level of sulfation and its position, or the presence of iduronate or glucuronate residues, most of the glycosidic linkages adopt similar disposition (figure 6).

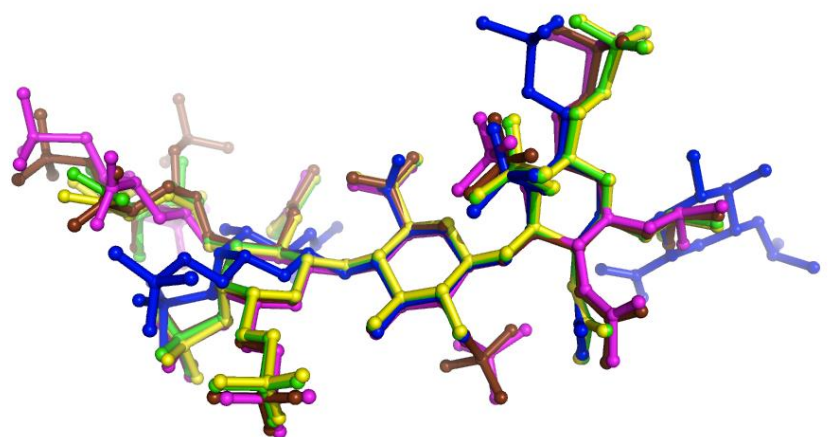

Figure 6. Superimposition of the minimized structures calculated for $\mathbf{1 5}$ (blue), 17 (purple), 19 (brown) and 21 (considered as two independent conformations: ${ }^{1} \mathrm{C}_{4}$ (green) and ${ }^{2} \mathrm{~S}_{0}$ (yellow)).

\section{STD and docking}

The solution structure of midkine has been previously determined by NMR. ${ }^{[25]}$ Midkine is structurally divided into two domains, $C$ - and $\mathrm{N}$-terminally located, joined by a hinge region. Although heparin binding and most of the biological activities of midkine are typically associated with the $C$-terminal domain, recent studies ${ }^{[25 b]}$ show that the $N$-terminal domain is also needed to mediate protein activity. For example, the interaction 
with fondaparinux (a synthetic heparin pentasaccharide) involves, not only the $C$-terminal half, but also the $N$-terminal domain and the hinge. In order to better understand the process of association between the CS oligosaccharides and midkine, we have performed a STD study using 15 and 19 complexes with midkine. We have applied the initial rate of the STD amplification factors approach to better quantify the STD effects and decoupling them from spurious relaxation effects (Supporting Information, tables S5 and S6 and figures S11 and S12). ${ }^{[26]}$ Both compounds showed moderate STD effects within similar range, extended along the entire chain (Figure 7). The largest STD effects are concentrated in the reducing end residue. Unfortunately, the signal overlapping prevented us from extract more precise structural data. Together with transfer NOE crosspeaks, the results are compatible with the association of both tetrasaccharides in an extended conformation while are simultaneously bound to both midkine domains that are close in space due to the hinged structure of the protein in solution, as it can be seen in some of the NMR structures. This can be seen considering the existence of STD in both sides and along all the tetrasaccharide, in both cases.
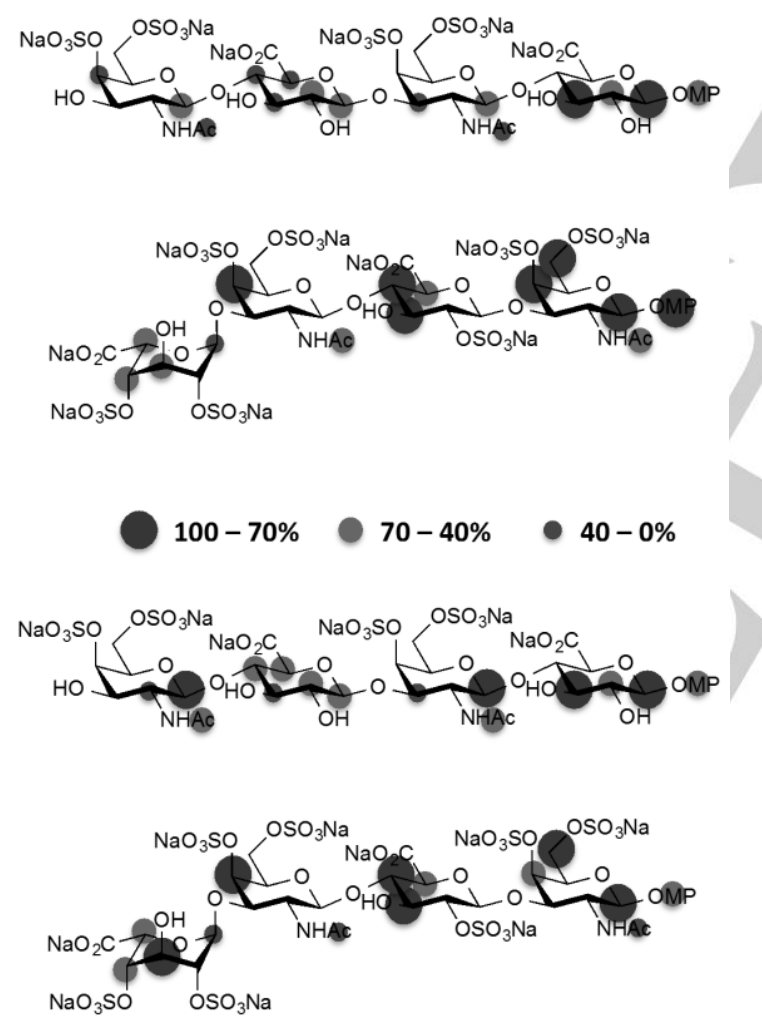

$$
2-1 \% \quad 1-0.5 \% \bigcirc 0.5-0 \%
$$

Figure 7. STD 0 relative (top) and absolute (bottom) values for 15 and 19.

We have performed a docking study using the coordinates of the NMR structure of midkine and the tetrasaccharides 15, 17, 19 and 21 (figures S13-S17). We have chosen one of the models from the NMR structures ensemble (model 3 from 10) calculated for midkine-A (pdb code: 2LUT) in which the two binding domains are close in the 3D structure. We first have constructed the complex using AutodockTools-1.5.6 from Autodock Vina either in automatic mode (considering all the residues within 10 $\AA$ ) or only the clusters described by Lim et al ${ }^{[25 b]}$ : Cluster 1: K82R84-K105; Cluster2: Q89-K90-L92; Cluster3: R38-R47; Cluster4: K48-K50-R52; Hinge: K58-K59. The complexes thus obtained were then subjected to Flexible Docking using Glyde as implemented in Maestro suite. In all the obtained models, the tetrasaccharides interact simultaneously with both glycosaminoglycan recognition domains of midkine-A, adopting the protein a folded conformation (Figure 8). Interestingly, all the carbohydrates are in the internal region of the protein loop formed by the two recognition domains, and surrounded by the unstructured regions of midkine, explaining the STD effects seen in both faces of the oligosaccharides (Figure 8). In addition, these structures are also compatible with transfer NOE results that account for extended glicosidic linkages. Unfortunately, all the attempts to quantify the STD using CORCEMA-ST did not converge to a satisfactory structure.

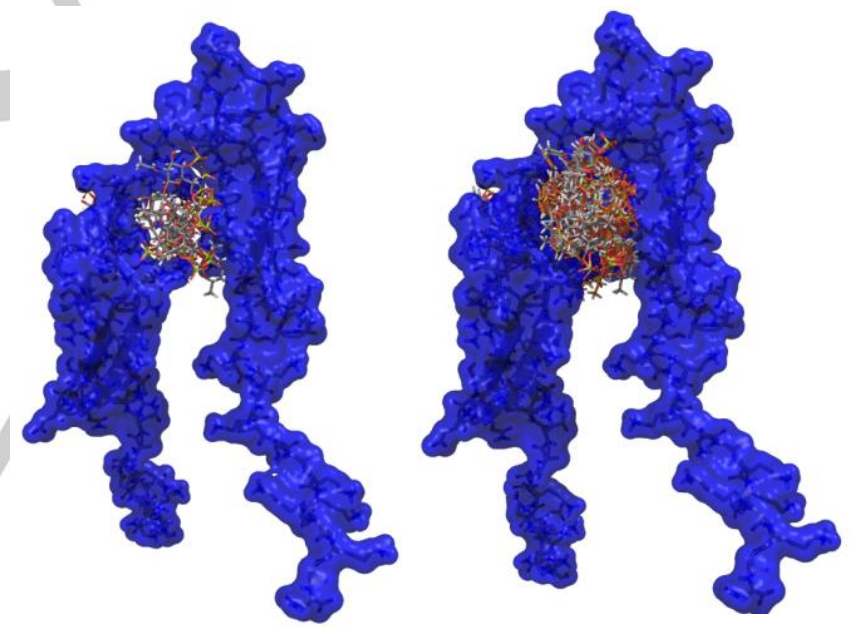

Figure 8. Docking-calculated structures for complexes between midkine and the studied tetrasaccharides. Superimposition of the structures with the best docking coefficient for one representative of all the tetrasaccharides (left), superimposition of all the structures obtained using docking 10 each (right).

\section{Conclusions}

We have developed an efficient approach for the synthesis of CS oligosaccharides following the GalNAc-GlcA sequence, illustrated by the preparation of CS-E tetrasaccharide 15. This strategy can be potentially extended to the synthesis of longer sequences with different sulfation motifs, by iterative glycosylation reactions and standard manipulation/sulfation of galactosamine 4-OH/6-OH groups, using disaccharide 7 as key building block. The present approach improves our previous strategy for CS oligomers with the alternative sequence GlcAGalNAc, in terms of total number of steps. Thus, the crucial 
cyclic sylilene group, which favors the undesired 1,2-cis glycosidic bond, is now introduced at the disaccharide stage, after the construction of the GalNAc-GlcA 1,2-trans linkage.

We have also demonstrated that our fluorescence polarization competition experiment is an excellent platform for the rapid analysis of the interactions between midkine and CS-like oligosaccharides. Our results show that the binding strength mainly depends on the density of sulfate groups: the relative affinities of CS-T related structures, in the low micromolar range, are much higher than those corresponding to the CS-E tetramers. Additionally, these data suggest that other structural features of CS-like molecules, such as the presence of hydrophobic benzyl protecting groups and IdoA units instead of GlcA, can also modulate the binding to midkine. Interestingly, we have shown that midkine binds to the CS-E tetrasaccharide $\mathbf{1 5}$, although with much less affinity (high micromolar range) than previously reported, probably due to the different nature of the binding experiments.

High-resolution NMR experiments provide interprotonic distances for the studied tetrasaccharides that are consistent with an extended conformation and a syn- $\Phi / \psi$ disposition for glycosidic bonds. Experimental coupling constants values show that all the monosaccharide rings adopt single chair conformations, except residue D of tetrasaccharide 21 that presents the typical conformational equilibrium of iduronic acid units between the chairs ${ }^{1} C_{4}$ and ${ }^{4} C_{1}$ and the skew-boat ${ }^{2} S_{O}$. These results were confirmed with molecular dynamic simulations in which the best fit between theoretical and experimental values was obtained when time averaged restrains were applied. The binding of the CS tetrasaccharides to midkine was also evaluated by STD-NMR and docking studies. STD experiments show that the tetrasaccharides interact in an extended conformation, along the entire chain, while docking results are compatible with a simultaneous association of the sugars with both domains of midkine, in a folded protein conformation. This binding mode, mainly in the internal region of the midkine formed by the two folded domains and the hinge, is in good agreement with that previously proposed for the interaction between midkine and fondaparinux.

\section{Experimental Section}

General synthetic procedures: Thin layer chromatography (TLC) analyses were performed on silica gel $60 \mathrm{~F}_{254}$ precoated on aluminium plates (Merck) and the compounds were detected by staining with sulfuric acid/ethanol (1:9), with cerium (IV) sulfate (10 $\mathrm{g}) /$ phosphomolybdic acid $(13 \mathrm{~g}) /$ sulfuric acid $(60 \mathrm{~mL})$ solution in water (1 $\mathrm{L})$, or with anisaldehyde solution [anisaldehyde $(25 \mathrm{~mL})$ with sulfuric acid $(25 \mathrm{~mL})$, ethanol $(450 \mathrm{~mL})$ and acetic acid $(1 \mathrm{~mL})]$, followed by heating at over $200^{\circ} \mathrm{C}$. Column chromatography was carried out on silica gel 60 (0.2-0.5 mm, 0.2-0.063 mm or 0.040-0.015 mm; Merck). Optical rotations were determined with a Perkin-Elmer 341 polarimeter. ${ }^{1} \mathrm{H}$ - and ${ }^{13} \mathrm{C}-\mathrm{NMR}$ spectra were acquired on Bruker DPX-300, Avance III-400 and DRX-500 spectrometers. Unit $A$ refers to the reducing end monosaccharide in the NMR data. Electrospray mass spectra (ESI MS) were carried out with an
Esquire 6000 ESI-Ion Trap from Bruker Daltonics. High resolution mass spectra (HR MS) were carried out by CITIUS (Universidad de Sevilla). Microwave-based sulfation reactions were performed using a Biotage Initiator Eight synthesizer in sealed reaction vessels.

\section{3,4,6-tri-O-acetyl-2-deoxy-2-trifluoroacetamido- $\alpha, \beta$-D-}

galactopyranose (2): Compound $\mathbf{1}(2.76 \mathrm{~g}, 6.23 \mathrm{mmol})$ was dissolved in $\mathrm{CH}_{2} \mathrm{Cl}_{2}(25 \mathrm{~mL})$ and hydrazine monohydrate $(25 \mathrm{~mL}$ of a $0.5 \mathrm{M}$ solution in $\mathrm{Py} / \mathrm{AcOH}$ 3:2) was added. After stirring at room temperature for $1 \mathrm{~h}$, the reaction mixture was quenched with acetone $(2 \mathrm{~mL})$. The mixture was diluted with $\mathrm{CH}_{2} \mathrm{Cl}_{2}$ and washed with $1 \mathrm{~m} \mathrm{HCl}$ aqueous solution, saturated $\mathrm{NaHCO}_{3}$ aqueous solution and $\mathrm{H}_{2} \mathrm{O}$. The organic layer was dried $\left(\mathrm{MgSO}_{4}\right)$, filtered and concentrated in vacuo. The residue was purified by column chromatography (hexane-EtOAc 2:1) to afford 2 (1.82 g, 73\%). TLC (hexane-EtOAc 3:2) Rf $0.31 ;{ }^{1} \mathrm{H}-\mathrm{NMR}\left(500 \mathrm{MHz}, \mathrm{CDCl}_{3}\right)$ (data for $\alpha$ anomer): $\delta 6.68\left(\mathrm{~d}, 1 \mathrm{H}, J_{\mathrm{NH}, 2}=9.5 \mathrm{~Hz}, \mathrm{NH}\right), 5.46\left(\mathrm{~d}, 1 \mathrm{H}, J_{3,4}=\right.$ $2.5 \mathrm{~Hz}, \mathrm{H}-4), 5.42\left(\mathrm{~d}, 1 \mathrm{H}, J_{1,2}=4.0 \mathrm{~Hz}, \mathrm{H}-1\right), 5.34\left(\mathrm{dd}, 1 \mathrm{H}, J_{2,3}=11.3 \mathrm{~Hz}\right.$ $\mathrm{H}-3), 4.60(\mathrm{~m}, 1 \mathrm{H}, \mathrm{H}-2), 4.48\left(\mathrm{t}, 1 \mathrm{H}, J_{5,6 \mathrm{a}}=J_{5,6 \mathrm{~b}}=6.3 \mathrm{~Hz}, \mathrm{H}-5\right), 4.17(\mathrm{~m}$, $2 \mathrm{H}, \mathrm{H}-6 \mathrm{a}, \mathrm{H}-6 \mathrm{~b}), 2.21,2.09,2.03$ (3s, 9H, OAc); ${ }^{13} \mathrm{C}-\mathrm{NMR}(75 \mathrm{MHz}$ $\left.\mathrm{CDCl}_{3}\right): \delta 171.1,171.0,170.4$ (3CO), $157.6\left(\mathrm{q}, \mathrm{COCF}_{3}\right), 115.6$ (q, $\mathrm{COCF}_{3}$ ), $91.4(\mathrm{C}-1), 67.8(\mathrm{C}-3), 67.3(\mathrm{C}-4), 66.6(\mathrm{C}-5), 62.1$ (C-6), 48.7 (C-2), 20.7, 20.6, $20.4\left(3 \mathrm{CH}_{3}\right)$; HR MS: $\mathrm{m} / \mathrm{z}$ : calcd for $\mathrm{C}_{14} \mathrm{H}_{18} \mathrm{~F}_{3} \mathrm{NO}_{9} \mathrm{Na}$ : 424.0826; found: $424.0826[\mathrm{M}+\mathrm{Na}]^{+}$.

\section{O-(3,4,6-tri-O-acetyl-2-deoxy-2-trifluoroacetamido- $\alpha, \beta-D-$}

galactopyranosyl) trichloroacetimidate (3): Trichloroacetonitrile (7.8 $\mathrm{mL}, 78 \mathrm{mmol})$ and catalytic DBU $(78 \mu \mathrm{L}, 0.52 \mathrm{mmol})$ were added to a solution of $2(2.08 \mathrm{~g}, 5.2 \mathrm{mmol})$ in dry $\mathrm{CH}_{2} \mathrm{Cl}_{2}(20 \mathrm{~mL})$. After stirring for 4 $\mathrm{h}$ at room temperature, the reaction mixture was concentrated to dryness. The residue was purified by a short silica gel column (hexane-EtOAc 3:1 $+1 \% \mathrm{Et}_{3} \mathrm{~N}$ ) to afford $3(2.04 \mathrm{~g}, 72 \%)$. TLC (hexane-EtOAc $2: 1+1 \% \mathrm{Et}_{3} \mathrm{~N}$ ) Rf 0.43; ${ }^{1} \mathrm{H}-\mathrm{NMR}\left(300 \mathrm{MHz}, \mathrm{CDCl}_{3}\right.$ ) (data for $\alpha$ anomer): $\delta 8.85(\mathrm{~s}, 1 \mathrm{H}$ $\mathrm{NH}(\mathrm{TCA})), 6.59\left(\mathrm{~d}, 1 \mathrm{H}, J_{\mathrm{NH}, 2}=9.0 \mathrm{~Hz}, \mathrm{NH}(\mathrm{TFA})\right), 6.47$ (d, $1 \mathrm{H}, J_{1,2}=3.6$ $\mathrm{Hz}, \mathrm{H}-1$ ), 5.53 (br d, $1 \mathrm{H}, \mathrm{H}-4), 5.35$ (dd, $1 \mathrm{H}, J_{3,4}=3.2 \mathrm{~Hz}, J_{2,3}=11.2 \mathrm{~Hz}$, $\mathrm{H}-3), 4.77(\mathrm{~m}, 1 \mathrm{H}, \mathrm{H}-2), 4.38(\mathrm{~m}, 1 \mathrm{H}, \mathrm{H}-5), 4.14(\mathrm{~m}, 2 \mathrm{H}, \mathrm{H}-6 \mathrm{a}, \mathrm{H}-6 \mathrm{~b})$, 2.20, 2.04, 2.03 (3s, 9H, OAc); ${ }^{13} \mathrm{C}-\mathrm{NMR}\left(75 \mathrm{MHz}, \mathrm{CDCl}_{3}\right): \delta 171.1$, 170.3, 170.1 (3CO), $160.1(\mathrm{C}=\mathrm{NH}), 157.5$ (q, COCF $)_{3}, 115.5$ (q, COCF $)$, 94.3 (C-1), $90.6\left(\mathrm{CCl}_{3}\right), 69.2$ (C-5), 67.7 (C-3), 66.3 (C-4), 61.1 (C-6), 48.2 (C-2), 20.62, 20.59, $20.4\left(3 \mathrm{CH}_{3}\right)$; ESI MS: $\mathrm{m} / \mathrm{z}$ : calcd for $\mathrm{C}_{16} \mathrm{H}_{18} \mathrm{Cl}_{3} \mathrm{~F}_{3} \mathrm{~N}_{2} \mathrm{O}_{9} \mathrm{Na}$ : 569.0; found: $569.1[\mathrm{M}+\mathrm{Na}]^{+}$.

Benzyl [4-Methoxyphenyl 2-O-benzoyl-3-O-benzyl-4-O-(3,4,6-tri-Oacetyl-2-deoxy-2-trifluoroacetamido- $\beta$-D-galactopyranosyl)- $\beta$-Dglucopyranoside] uronate (5): Donor $3(2.02 \mathrm{~g}, 3.70 \mathrm{mmol})$ and acceptor $4(1.40 \mathrm{~g}, 2.40 \mathrm{mmol})$ were dissolved in dry $\mathrm{CH}_{2} \mathrm{Cl}_{2}(30 \mathrm{~mL})$ in the presence of freshly activated $4 \AA$ molecular sieves. After stirring for 15 min at $0^{\circ} \mathrm{C}$, TMSOTf $(134 \mu \mathrm{L}, 0.74 \mathrm{mmol})$ was added under an argon atmosphere. After stirring for $15 \mathrm{~min}$ at $0^{\circ} \mathrm{C}$, the reaction mixture was neutralized with $\mathrm{Et}_{3} \mathrm{~N}$, filtered and concentrated to dryness. The residue was purified by column chromatography (hexane-EtOAc $3: 1 \rightarrow 2: 1$ ) to afford $5(1.96 \mathrm{~g}, 85 \%)$. TLC (hexane-EtOAc 2:1) Rf 0.16; [a $]^{20}{ }_{D}-4^{\circ}(c 1.0$, $\left.\mathrm{CHCl}_{3}\right) ;{ }^{1} \mathrm{H}-\mathrm{NMR}\left(400 \mathrm{MHz}, \mathrm{CDCl}_{3}\right): \delta 7.98(\mathrm{~d}, 2 \mathrm{H}, \mathrm{Ar}), 7.60(\mathrm{t}, 1 \mathrm{H}, \mathrm{Ar})$, 7.49-7.44 (m, 7H, Ar), 7.19-7.13 (m, 5H, Ar), $6.90(\mathrm{~m}, 2 \mathrm{H}, \mathrm{Ar}), 6.73(\mathrm{~m}$ $2 \mathrm{H}, \mathrm{Ar}), 6.58\left(\mathrm{~d}, 1 \mathrm{H}, \mathrm{J}_{\mathrm{NH}, 2}=8.8 \mathrm{~Hz}, \mathrm{NH}\right), 5.48\left(\mathrm{dd}, 1 \mathrm{H}, J_{2,3}=8.8 \mathrm{~Hz}, \mathrm{H}-2\right)$, $5.39\left(\mathrm{~d}, 1 \mathrm{H}, \mathrm{CH}_{2}(\mathrm{Bn})\right), 5.22\left(\mathrm{~d}, 1 \mathrm{H}, J_{3,4}=2.8 \mathrm{~Hz}, \mathrm{H}-4\right.$ ) $), 5.13(\mathrm{~d}, 1 \mathrm{H}$ $\left.\mathrm{CH}_{2}(\mathrm{Bn})\right), 5.04\left(\mathrm{~d}, 1 \mathrm{H}, \mathrm{J}_{1,2}=7.2 \mathrm{~Hz}, \mathrm{H}-1\right), 4.87\left(\mathrm{~d}, 1 \mathrm{H}, \mathrm{CH}_{2}(\mathrm{Bn})\right)$, 4.68$4.62\left(\mathrm{~m}, 2 \mathrm{H}, \mathrm{H}-3^{\prime}, \mathrm{CH}_{2}(\mathrm{Bn})\right), 4.25\left(\mathrm{~m}, 1 \mathrm{H}, \mathrm{H}-2^{\prime}\right), 4.16(\mathrm{t}, 1 \mathrm{H}, \mathrm{H}-4), 4.09(\mathrm{~m}$, $\left.2 \mathrm{H}, \mathrm{H}-1^{\prime}, \mathrm{H}-5\right), 3.97\left(\mathrm{dd}, 1 \mathrm{H}, \mathrm{J}_{6 \mathrm{a}, 6 \mathrm{~b}}=11.2 \mathrm{~Hz}, \mathrm{H}-6\right.$ 'a), 3.89-3.82 (m, 2H, H3, H-6'b), 3.75 (s, 3H, Me (OMP)), 3.43 (t, $1 \mathrm{H}, J_{5,6 \mathrm{a}}=J_{5,6 \mathrm{~b}}=7.0 \mathrm{~Hz}, \mathrm{H}-5^{\prime}$ ), 2.15, 2.06, $2.02(3 \mathrm{~s}, 9 \mathrm{H}, \mathrm{OAc}) ;{ }^{13} \mathrm{C}-\mathrm{NMR}\left(100 \mathrm{MHz}, \mathrm{CDCl}_{3}\right): \delta 170.4$ 170.3, 170.1, 168.9, 165.0 (5CO), $157.6\left(\mathrm{q}, \mathrm{COCF}_{3}\right), 155.8-114.5(\mathrm{Ar})$ $115.8\left(\mathrm{q}, \mathrm{COCF}_{3}\right), 100.8(\mathrm{C}-1), 100.4\left(\mathrm{C}-1^{\prime}\right), 79.4(\mathrm{C}-3), 78.5(\mathrm{C}-4), 75.0$ $\left(\mathrm{CH}_{2}(\mathrm{Bn})\right), 74.4(\mathrm{C}-5), 72.7(\mathrm{C}-2), 70.8,70.6\left(\mathrm{C}-3^{\prime}, \mathrm{C}-5^{\prime}\right), 68.0\left(\mathrm{CH}_{2}(\mathrm{Bn})\right)$, 66.0 (C-4'), 60.6 (C-6'), 55.6 (Me (OMP)), 51.0 (C-2'), 20.7, 20.6, 20.4 
$\left(3 \mathrm{CH}_{3}\right)$; HR MS: $\mathrm{m} / \mathrm{z}$ : calcd for $\mathrm{C}_{48} \mathrm{H}_{48} \mathrm{~F}_{3} \mathrm{NO}_{17} \mathrm{Na}$ : 990.2767; found: $990.2764[\mathrm{M}+\mathrm{Na}]^{+}$.

Benzyl [4-Methoxyphenyl 2-O-benzoyl-3-O-benzyl-4-O-(2-deoxy-2trifluoroacetamido- $\beta$-D-galactopyranosyl)- $\beta$-D-glucopyranoside] uronate (6): Compound 5 (1.96 g, $2.03 \mathrm{mmol})$ was dissolved in $\mathrm{CH}_{2} \mathrm{Cl}_{2} / \mathrm{MeOH}(18 \mathrm{~mL} / 2 \mathrm{~mL}$ ) and $p$-toluenesulfonic acid was added (1.16 $\mathrm{g}, 6.08 \mathrm{mmol}$ ). After stirring for $11 \mathrm{~h}$ at room temperature, the reaction mixture was diluted with $\mathrm{CH}_{2} \mathrm{Cl}_{2}$ and washed with saturated aqueous $\mathrm{NaHCO}_{3}$ and $\mathrm{H}_{2} \mathrm{O}$. The organic phase was dried $\left(\mathrm{MgSO}_{4}\right)$, filtered and concentrated to dryness. The residue was purified by column chromatography $\left(\mathrm{CH}_{2} \mathrm{Cl}_{2}-\mathrm{MeOH} 40: 1\right)$ to afford 6 as a amorphous white solid (884 mg, 52\%). TLC $\left(\mathrm{CH}_{2} \mathrm{Cl}_{2}-\mathrm{MeOH} 30: 1\right)$ Rf 0.20; $[\alpha]^{20} \mathrm{D}+22^{\circ}(c 1.0$ $\mathrm{CHCl}_{3}$ ); ${ }^{1} \mathrm{H}-\mathrm{NMR}\left(500 \mathrm{MHz}, \mathrm{CDCl}_{3}\right): \delta 8.01(\mathrm{~d}, 2 \mathrm{H}, \mathrm{Ar}), 7.60(\mathrm{t}, 1 \mathrm{H}, \mathrm{Ar})$, 7.49-7.39 (m, 8H, Ar, NH), 7.21-7.18 (m, 5H, Ar), $6.92(\mathrm{~m}, 2 \mathrm{H}, \mathrm{Ar}), 6.74$ $(\mathrm{m}, 2 \mathrm{H}, \mathrm{Ar}), 5.50(\mathrm{t}, 1 \mathrm{H}, \mathrm{H}-2), 5.37\left(\mathrm{~d}, 1 \mathrm{H}, \mathrm{CH}_{2}(\mathrm{Bn})\right), 5.19(\mathrm{~d}, 1 \mathrm{H}$, $\left.\mathrm{CH}_{2}(\mathrm{Bn})\right), 5.06\left(\mathrm{~d}, 1 \mathrm{H}, \mathrm{J}_{1,2}=7.5 \mathrm{~Hz}, \mathrm{H}-1\right), 4.90\left(\mathrm{~d}, 1 \mathrm{H}, \mathrm{CH}_{2}(\mathrm{Bn})\right), 4.63(\mathrm{~d}$, $\left.1 \mathrm{H}, \mathrm{CH}_{2}(\mathrm{Bn})\right)$, 4.16-4.09 (m, 2H, H-4, H-5), 3.98 (m, 2H, H-1', H-2'), 3.84 $\left(\mathrm{t}, 1 \mathrm{H}, J_{2,3}=J_{3,4}=9.0 \mathrm{~Hz}, \mathrm{H}-3\right), 3.80\left(\mathrm{br} \mathrm{s}, 1 \mathrm{H}, \mathrm{H}-4^{\prime}\right), 3.76(\mathrm{~s}, 3 \mathrm{H}, \mathrm{Me}$ (OMP)), 3.67 (dd, $1 \mathrm{H}, J_{5,6 \mathrm{a}}=6.0 \mathrm{~Hz}, \mathrm{~J}_{6 \mathrm{a}, 6 \mathrm{~b}}=11.5 \mathrm{~Hz}, \mathrm{H}-6 \mathrm{\prime}$ ) $), 3.61$ (br d, $\left.1 \mathrm{H}, \mathrm{H}-6^{\prime} \mathrm{b}\right), 3.30$ (br d, $\left.1 \mathrm{H}, \mathrm{H}-3^{\prime}\right), 3.05$ (m, $\left.1 \mathrm{H}, \mathrm{H}-5^{\prime}\right) ;{ }^{13} \mathrm{C}-\mathrm{NMR}(100 \mathrm{MHz}$, $\mathrm{CDCl}_{3}-\mathrm{CD}_{3} \mathrm{OD}$ 9:1): $\delta$ 168.0, $165.2(2 \times \mathrm{CO}), 158.4$ (q, $\left.\mathrm{COCF}_{3}\right), 155.5-$ $114.3(\mathrm{Ar}), 115.9$ (q, $\left.\mathrm{COCF}_{3}\right), 100.6$ (C-1), $100.0\left(\mathrm{C}-1^{\prime}\right), 79.7$ (C-3), 76.2 (C-4), $75.8\left(\mathrm{CH}_{2}(\mathrm{Bn}), \mathrm{C}^{\prime} 5^{\prime}\right), 74.2$ (C-5), 72.4 (C-2), 70.8 (C-3'), 68.3 (C-4'), $67.5\left(\mathrm{CH}_{2}(\mathrm{Bn})\right), 61.8\left(\mathrm{C}-6^{\prime}\right), 55.3(\mathrm{Me}(\mathrm{OMP})), 53.6\left(\mathrm{C}-2^{\prime}\right)$ ) HR MS: $\mathrm{m} / \mathrm{z}$ : calcd for $\mathrm{C}_{42} \mathrm{H}_{42} \mathrm{~F}_{3} \mathrm{NO}_{14} \mathrm{Na}$ : 864.2450; found: $864.2447[\mathrm{M}+\mathrm{Na}]^{+}$.

Benzyl [4-Methoxyphenyl 2-O-benzoyl-3-O-benzyl-4-O-(4,6-O-di-tertbutylsilylene-2-deoxy-2-trifluoroacetamido- $\beta$-D-galactopyranosyl)- $\beta$ D-glucopyranoside] uronate (7): Compound $6(100 \mathrm{mg}, 0.12 \mathrm{mmol})$ was dissolved in dry Py $(4 \mathrm{~mL})$ and cooled $\left(0^{\circ} \mathrm{C}\right)$. Di-tert-butylsilyl bis(trifluoromethanesulfonate) $(42 \mu \mathrm{L}, 0.13 \mathrm{mmol})$ was added and the mixture was stirred at room temperature for $25 \mathrm{~min}$. The reaction was quenched with $\mathrm{MeOH}(0.5 \mathrm{~mL})$, diluted with $\mathrm{EtOAc}(50 \mathrm{~mL})$, and washed with $1 \mathrm{~m} \mathrm{HCl}$, saturated aqueous $\mathrm{NaHCO}_{3}$, and $\mathrm{H}_{2} \mathrm{O}$. The organic phase was dried $\left(\mathrm{MgSO}_{4}\right)$, filtered and concentrated to dryness. The residue was purified by column chromatography (toluene-EtOAc $5: 1$ ) to afford 7 as a colorless oil $(98 \mathrm{mg}, 84 \%)$. TLC (toluene-EtOAc 5:1) Rf 0.29 ; [a] ${ }^{20} \mathrm{D}$ +33으 (c 1.0, $\left.\mathrm{CHCl}_{3}\right) ;{ }^{1} \mathrm{H}-\mathrm{NMR}\left(400 \mathrm{MHz}, \mathrm{CDCl}_{3}\right): \delta 7.94$ (d, $\left.2 \mathrm{H}, \mathrm{Ar}\right), 7.60$ (t, 1H, Ar), 7.46-7.38 (m, 7H, Ar), 7.22-7.07 (m, 6H, Ar, NH), $6.90(\mathrm{~m}, 2 \mathrm{H}$, Ar), $6.72(\mathrm{~m}, 2 \mathrm{H}, \mathrm{Ar}), 5.49(\mathrm{t}, 1 \mathrm{H}, \mathrm{H}-2), 5.34\left(\mathrm{~d}, 1 \mathrm{H}, \mathrm{CH}_{2}(\mathrm{Bn})\right), 5.12(\mathrm{~d}, 1 \mathrm{H}$ $\left.\mathrm{CH}_{2}(\mathrm{Bn})\right), 5.05\left(\mathrm{~d}, 1 \mathrm{H}, \mathrm{J}_{1,2}=6.8 \mathrm{~Hz}, \mathrm{H}-1\right), 5.00\left(\mathrm{~d}, 1 \mathrm{H}, \mathrm{CH}_{2}(\mathrm{Bn})\right), 4.63(\mathrm{~d}$, $1 \mathrm{H}, \mathrm{CH}_{2}(\mathrm{Bn})$ ), 4.30-4.18 (m, 6H, H-4, H-1', H-2', H-4', H-6'a, H-6'b), 4.14 (d, $\left.1 \mathrm{H}, J_{4,5}=9.2 \mathrm{~Hz}, \mathrm{H}-5\right), 3.89$ (t, $\left.1 \mathrm{H}, J_{2,3}=J_{3,4}=8.4 \mathrm{~Hz}, \mathrm{H}-3\right), 3.75$ (s, $3 \mathrm{H}, \mathrm{Me}(\mathrm{OMP})$ ), 3.21 (dd, $1 \mathrm{H}, J_{2,3}=9.6 \mathrm{~Hz}, J_{3,4}=2.8 \mathrm{~Hz}, \mathrm{H}-3^{\prime}$ ), 3.08 (br s $\left.1 \mathrm{H}, \mathrm{H}-5^{\prime}\right), 1.09,1.05\left(2 \mathrm{~s}, 18 \mathrm{H}, \mathrm{C}\left(\mathrm{CH}_{3}\right)_{3}\right) ;{ }^{13} \mathrm{C}-\mathrm{NMR}\left(100 \mathrm{MHz}, \mathrm{CDCl}_{3}\right): \delta$ 170.0, 165.1 (2 x CO), $158.2\left(\mathrm{q}, \mathrm{COCF}_{3}\right), 155.7-114.5(\mathrm{Ar}), 116.1$ (q, $\mathrm{COCF}_{3}$ ), 102.0 (C-1'), 100.6 (C-1), 80.5 (C-4), $79.7(\mathrm{C}-3), 75.5\left(\mathrm{CH}_{2}(\mathrm{Bn})\right)$ 74.5 (C-5), 73.3 (C-3'), 73.0 (C-2), 72.1 (C-5'), 71.9 (C-4'), 68.0 $\left(\mathrm{CH}_{2}(\mathrm{Bn})\right), 66.5$ (C-6'), 55.6 (Me (OMP)), 53.0 (C-2'), 27.6, 27.4 $\left(\mathrm{C}\left(\mathrm{CH}_{3}\right)_{3}\right), \quad 23.4, \quad 20.6\left(\mathrm{C}\left(\mathrm{CH}_{3}\right)_{3}\right) ; \quad \mathrm{HR} \quad \mathrm{MS}: \mathrm{m} / \mathrm{z}$ : calcd for $\mathrm{C}_{50} \mathrm{H}_{58} \mathrm{~F}_{3} \mathrm{NO}_{14} \mathrm{NaSi}$ : 1004.3471 ; found: $1004.3451[\mathrm{M}+\mathrm{Na}]^{+}$.

Benzyl [4-Methoxyphenyl 2-O-benzoyl-3-O-benzyl-4-O-(4,6-O-di-tertbutylsilylene-2-deoxy-3-O-levulinoyl-2-trifluoroacetamido- $\beta$-D-

galactopyranosyl)- $\beta$-D-glucopyranoside] uronate (8): $\mathrm{Lev}_{2} \mathrm{O}$ preparation: $\mathrm{LevOH}(241 \mu \mathrm{L}, 2.34 \mathrm{mmol})$ was added at $0^{\circ} \mathrm{C}$ to a solution of 1,3-dicyclohexylcarbodiimide (241 $\mathrm{mg}, 1.17 \mathrm{mmol})$ in $\mathrm{CH}_{2} \mathrm{Cl}_{2}(4 \mathrm{~mL})$. After stirring $5 \mathrm{~min}$ at room temperature, the mixture was cooled and filtered, and the urea precipitate was washed with additional $\mathrm{CH}_{2} \mathrm{Cl}_{2}$ (2 $\mathrm{mL}$ ), to give $6 \mathrm{~mL}$ of a $0.20 \mathrm{~m} \mathrm{Lev}{ }_{2} \mathrm{O}$ solution.

$\operatorname{Lev}_{2} \mathrm{O}\left(6 \mathrm{~mL}\right.$ of a $0.20 \mathrm{~m}$ solution in $\mathrm{CH}_{2} \mathrm{Cl}_{2}$ ) was added at room temperature to a mixture of $7(380 \mathrm{mg}, 0.39 \mathrm{mmol})$ and DMAP $(7 \mathrm{mg}$,
$0.06 \mathrm{mmol}$ ). The mixture was stirred for $1 \mathrm{~h}$, diluted with $\mathrm{CH}_{2} \mathrm{Cl}_{2}$, and washed with saturated aqueous $\mathrm{NaHCO}_{3}$, and $\mathrm{H}_{2} \mathrm{O}$. The organic phase was dried $\left(\mathrm{MgSO}_{4}\right)$, filtered and concentrated to dryness. The residue was purified by column chromatography (toluene-EtOAc $5: 1$ ) to afford 8 as a white foam (364 mg, 87\%). TLC (toluene-EtOAc 4:1) $R_{f} 0.37 ;[\alpha]^{20}$ $+30.5^{\circ}$ (c 1.0, $\left.\mathrm{CHCl}_{3}\right) ;{ }^{1} \mathrm{H}-\mathrm{NMR}\left(500 \mathrm{MHz}, \mathrm{CDCl}_{3}\right): \delta 7.92$ (d, $\left.2 \mathrm{H}, \mathrm{Ar}\right)$ $7.57(\mathrm{t}, 1 \mathrm{H}, \mathrm{Ar}), 7.44-7.38(\mathrm{~m}, 7 \mathrm{H}, \mathrm{Ar}), 7.21-7.07(\mathrm{~m}, 5 \mathrm{H}, \mathrm{Ar}), 6.91-6.86$ (m, 3H, Ar, NH), $6.70(\mathrm{~m}, 2 \mathrm{H}, \mathrm{Ar}), 5.46(\mathrm{t}, 1 \mathrm{H}, \mathrm{H}-2), 5.30\left(\mathrm{~d}, 1 \mathrm{H}, \mathrm{CH}_{2}(\mathrm{Bn})\right)$, $5.09\left(\mathrm{~d}, 1 \mathrm{H}, \mathrm{CH}_{2}(\mathrm{Bn})\right), 5.05\left(\mathrm{~d}, 1 \mathrm{H}, \mathrm{J}_{1,2}=6.8 \mathrm{~Hz}, \mathrm{H}-1\right), 4.96(\mathrm{~d}, 1 \mathrm{H}$, $\left.\mathrm{CH}_{2}(\mathrm{Bn})\right), 4.64\left(\mathrm{~d}, 1 \mathrm{H}, \mathrm{CH}_{2}(\mathrm{Bn})\right), 4.54\left(\mathrm{~m}, 2 \mathrm{H}, \mathrm{H}-2^{\prime}, \mathrm{H}-3^{\prime}\right), 4.49(\mathrm{br} \mathrm{s}, 1 \mathrm{H}$ $\left.\mathrm{H}-4^{\prime}\right), 4.40\left(\mathrm{~d}, 1 \mathrm{H}, J_{1,2}=7.7 \mathrm{~Hz}, \mathrm{H}-1^{\prime}\right), 4.24(\mathrm{t}, 1 \mathrm{H}, \mathrm{H}-4), 4.18(\mathrm{~m}, 2 \mathrm{H}, \mathrm{H}-$ 6'a, H-6'b), $4.11\left(\mathrm{~d}, 1 \mathrm{H}, \mathrm{J}_{4,5}=9.0 \mathrm{~Hz}, \mathrm{H}-5\right), 3.89\left(\mathrm{t}, 1 \mathrm{H}, J_{2,3}=J_{3,4}=8.2 \mathrm{~Hz}\right.$, $\mathrm{H}-3), 3.73$ (s, 3H, Me (OMP)), 3.06 (br s, $\left.1 \mathrm{H}, \mathrm{H}-5^{\prime}\right), 2.82-2.56(\mathrm{~m}, 4 \mathrm{H}$, $\left.\mathrm{CH}_{2}(\mathrm{Lev})\right), 2.20\left(\mathrm{~s}, 3 \mathrm{H}, \mathrm{CH}_{3}(\mathrm{Lev})\right), 1.04,1.02\left(2 \mathrm{~s}, 18 \mathrm{H}, \mathrm{C}\left(\mathrm{CH}_{3}\right)_{3}\right)$; ${ }^{13} \mathrm{C}-\mathrm{NMR}\left(125 \mathrm{MHz}, \mathrm{CDCl}_{3}\right): \delta 206.7,172.7,170.0,165.4(4 \times \mathrm{CO})$, 157.9 (q, $\left.\mathrm{COCF}_{3}\right), 156.0-114.8(\mathrm{Ar}), 116.2\left(\mathrm{q}, \mathrm{COCF}_{3}\right), 102.3\left(\mathrm{C}-1^{\prime}\right)$, 100.9 (C-1), 80.4 (C-4), 79.9 (C-3), $75.4\left(\mathrm{CH}_{2}(\mathrm{Bn})\right), 74.9$ (C-5), 74.1 (C3'), 73.4 (C-2), 72.3 (C-5'), 69.8 (C-4'), $68.2\left(\mathrm{CH}_{2}(\mathrm{Bn})\right), 66.9$ (C-6'), 55.9 (Me (OMP)), 50.3 (C-2'), $38.1 \quad\left(\mathrm{CH}_{2}(\mathrm{Lev})\right), \quad 30.0\left(\mathrm{CH}_{3}(\mathrm{Lev})\right), \quad 28.6$

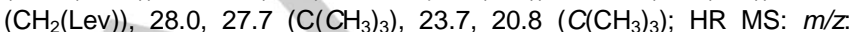
calcd for $\mathrm{C}_{55} \mathrm{H}_{64} \mathrm{~F}_{3} \mathrm{NO}_{16} \mathrm{NaSi}$ : 1102.3839 ; found: $1102.3842[\mathrm{M}+\mathrm{Na}]^{+}$.

\section{Benzyl [2-O-benzoyl-3-O-benzyl-4-O-(4,6-O-di-tert-butylsilylene-2-} deoxy-3-O-levulinoyl-2-trifluoroacetamido- $\beta$-D-galactopyranosyl)$\alpha, \beta$-D-glucopyranose] uronate (9): CAN $(2.7 \mathrm{~mL}$ of a $0.63 \mathrm{~m}$ solution in $\mathrm{H}_{2} \mathrm{O}$ ) was added to a solution of $8(456 \mathrm{mg}, 0.422 \mathrm{mmol})$ in $\mathrm{CH}_{2} \mathrm{Cl}_{2} / \mathrm{MeCN}(1: 2 ; 24.3 \mathrm{~mL})$. After stirring for $1 \mathrm{~h}$ at room temperature, the reaction mixture was diluted with EtOAc, washed with $\mathrm{H}_{2} \mathrm{O}$, saturated aqueous $\mathrm{NaHCO}_{3}$, and $\mathrm{H}_{2} \mathrm{O}$. The organic phase was dried $\left(\mathrm{MgSO}_{4}\right)$, filtered and concentrated to dryness. The residue was purified by column chromatography (toluene-EtOAc 4:1) to afford 9 as an orange foam (336 $\mathrm{mg}, 82 \%$, mixture of $\alpha / \beta$ anomers). TLC (toluene-EtOAc 4:1) Rf 0.24; ${ }^{1} \mathrm{H}$-NMR $\left(400 \mathrm{MHz}, \mathrm{CDCl}_{3}\right.$ ) (data for $\alpha$ anomer): $\delta 7.96(\mathrm{~d}, 2 \mathrm{H}, \mathrm{Ar}), 7.57(\mathrm{t}$, $1 \mathrm{H}, \mathrm{Ar}), 7.49-7.12(\mathrm{~m}, 12 \mathrm{H}, \mathrm{Ar}), 7.06\left(\mathrm{~d}, 1 \mathrm{H}, \mathrm{J}_{2, \mathrm{NH}}=8.3 \mathrm{~Hz}, \mathrm{NH}\right), 5.55(\mathrm{t}$, $1 \mathrm{H}, \mathrm{H}-1), 5.41$ (d, $\left.1 \mathrm{H}, \mathrm{CH}_{2}(\mathrm{Bn})\right), 5.15-5.08\left(\mathrm{~m}, 2 \mathrm{H}, \mathrm{CH}_{2}(\mathrm{Bn}), \mathrm{H}-2\right), 5.00$ (d, $\left.1 \mathrm{H}, \mathrm{CH}_{2}(\mathrm{Bn})\right)$, $4.66\left(\mathrm{~d}, 1 \mathrm{H}, \mathrm{CH}_{2}(\mathrm{Bn})\right)$, 4.54-4.46 (m, 4H, H-2', H-3', H-4', $\mathrm{H}-5), 4.29\left(\mathrm{~d}, 1 \mathrm{H}, J_{1,2}=7.9 \mathrm{~Hz}, \mathrm{H}-1\right.$ '), $4.20-4.10(\mathrm{~m}, 3 \mathrm{H}, \mathrm{H}-3, \mathrm{H}-6$ ' $\mathrm{a}, \mathrm{H}-$ 6'b), $4.02\left(\mathrm{t}, 1 \mathrm{H}, J_{3,4}=J_{4,5}=8.2 \mathrm{~Hz}, \mathrm{H}-4\right), 3.76\left(\mathrm{~d}, 1 \mathrm{H}, J_{1, \mathrm{OH}}=4.7 \mathrm{~Hz}\right.$, $\mathrm{OH}), 2.96$ (br s, $\left.1 \mathrm{H}, \mathrm{H}-5^{\prime}\right), 2.81-2.56\left(\mathrm{~m}, 4 \mathrm{H}, \mathrm{CH}_{2}(\mathrm{Lev})\right), 2.20(\mathrm{~s}, 3 \mathrm{H}$, $\left.\mathrm{CH}_{3}(\mathrm{Lev})\right), 1.04,1.01\left(2 \mathrm{~s}, 18 \mathrm{H}, \mathrm{C}\left(\mathrm{CH}_{3}\right)_{3}\right) ;{ }^{13} \mathrm{C}-\mathrm{NMR}\left(100 \mathrm{MHz}, \mathrm{CDCl}_{3}\right)$ (data for $\alpha$ anomer): $\delta 206.5,172.3,170.7,165.8(4 \times C O), 157.7$ (q, $\mathrm{COCF}_{3}$ ), 138.1-125.3 (Ar), 116.0 (q, COCF $), 101.5\left(\mathrm{C}-1^{\prime}\right), 90.1(\mathrm{C}-1)$ 79.9 (C-4), 76.8 (C-3), $75.2\left(\mathrm{CH}_{2}(\mathrm{Bn})\right), 73.7$ (C-5 or C-3'), $72.2(\mathrm{C}-2)$, $71.8\left(\mathrm{C}-5^{\prime}\right), 70.8$ (C-5 or C-3'), $69.5\left(\mathrm{C}-4^{\prime}\right), 67.8\left(\mathrm{CH}_{2}(\mathrm{Bn})\right), 66.5\left(\mathrm{C}-6^{\prime}\right)$, 50.0 (C-2'), $37.8\left(\mathrm{CH}_{2}(\mathrm{Lev})\right), 29.7\left(\mathrm{CH}_{3}(\mathrm{Lev})\right), 28.2\left(\mathrm{CH}_{2}(\mathrm{Lev})\right), 27.6,27.3$

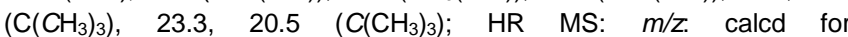
$\mathrm{C}_{48} \mathrm{H}_{58} \mathrm{~F}_{3} \mathrm{NO}_{15} \mathrm{NaSi}$ : 996.3420; found: $996.3421[\mathrm{M}+\mathrm{Na}]^{+}$.

O-[Benzyl 2-O-benzoyl-3-O-benzyl-4-O-(4,6-O-di-tert-butylsilylene-2deoxy-3-O-levulinoyl-2-trifluoroacetamido- $\beta$-D-galactopyranosyl)$\alpha, \beta$-D-glucopyranosyluronate] trichloroacetimidate (10): Trichloroacetonitrile $(1.26 \mathrm{~mL}, 12.6 \mathrm{mmol})$ and $\mathrm{K}_{2} \mathrm{CO}_{3}(41 \mathrm{mg}, 0.30$ $\mathrm{mmol}$ ) were added to 9 (246 mg, $0.25 \mathrm{mmol})$ in dry $\mathrm{CH}_{2} \mathrm{Cl}_{2}(4 \mathrm{~mL})$ under an argon atmosphere. After stirring at room temperature for $8 \mathrm{~h}$, the mixture was filtered and concentrated in vacuo to give 10 as a brown oil (279 mg, quantitative, mixture of $\alpha / \beta$ anomers). TLC $\left(\mathrm{CH}_{2} \mathrm{Cl}_{2}-\mathrm{MeOH} 80: 1\right)$ Rf 0.67 and $0.53 ;{ }^{1} \mathrm{H}-\mathrm{NMR}\left(500 \mathrm{MHz}, \mathrm{CDCl}_{3}\right.$ ) (data for a $1: 1 \mathrm{\alpha} / \beta$ mixture) $\delta$ 8.66, $8.62(2 \mathrm{~s}, 2 \mathrm{H}, \mathrm{NHa}$ and $\mathrm{NH} \beta), 7.89-7.10(\mathrm{~m}, 31 \mathrm{H}, \mathrm{Ar}$ and $\mathrm{NH})$, $6.92(\mathrm{br} \mathrm{s}, 1 \mathrm{H}, \mathrm{NH}), 6.59\left(\mathrm{~d}, 1 \mathrm{H}, J_{1,2}=3.7 \mathrm{~Hz}, \mathrm{H}-1 \alpha\right), 6.01\left(\mathrm{~d}, 1 \mathrm{H}, J_{1,2}=\right.$

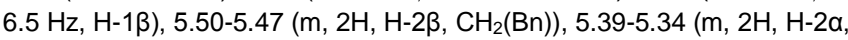
$\left.\mathrm{CH}_{2}(\mathrm{Bn})\right), 5.14\left(\mathrm{~m}, 2 \mathrm{H}, \mathrm{CH}_{2}(\mathrm{Bn})\right), 4.94\left(\mathrm{~d}, 1 \mathrm{H}, \mathrm{CH}_{2}(\mathrm{Bn})\right), 4.89(\mathrm{~d}, 1 \mathrm{H}$, $\left.\mathrm{CH}_{2}(\mathrm{Bn})\right)$, $4.66\left(\mathrm{~m}, 2 \mathrm{H}, \mathrm{CH}_{2}(\mathrm{Bn})\right)$, 4.52-3.86 (m, 18H, H-3, H-4, H-5, H-1', $\mathrm{H}-2^{\prime}, \mathrm{H}-3^{\prime}, \mathrm{H}-4$ ', H-6'a, H-6'b), 2.96 (br s, $\left.1 \mathrm{H}, \mathrm{H}-5^{\prime} \beta\right), 2.79-2.74$ (m, 4H, $\left.\mathrm{CH}_{2}(\mathrm{Lev})\right), 2.69$ (br s, $\left.1 \mathrm{H}, \mathrm{H}-5^{\prime} \alpha\right), 2.59\left(\mathrm{~m}, 4 \mathrm{H}, \mathrm{CH}_{2}(\mathrm{Lev})\right), 2.19$ (2s, 6H, 
$\left.\mathrm{CH}_{3}(\mathrm{Lev})\right)$, $1.02-0.99\left(2 \mathrm{~s}, 36 \mathrm{H}, \quad \mathrm{C}\left(\mathrm{CH}_{3}\right)_{3}\right) ; \mathrm{ESI} \mathrm{MS}: \mathrm{m} / \mathrm{z}$ : calcd for $\mathrm{C}_{50} \mathrm{H}_{58} \mathrm{Cl}_{3} \mathrm{~F}_{3} \mathrm{~N}_{2} \mathrm{O}_{15} \mathrm{SiNa}$ : 1141.3; found: $1141.4[\mathrm{M}+\mathrm{Na}]^{+}$

\begin{abstract}
4-Methoxyphenyl O-(4,6-O-di-tert-butylsilylene-2-deoxy-3-Olevulinoyl-2-trifluoroacetamido- $\beta$-D-galactopyranosyl)-(1 $\rightarrow 4)-0$ (benzyl 2-O-benzoyl-3-O-benzyl- $\beta$-D-glucopyranosyluronate)-(1 $\rightarrow 3$ )$O$-(4,6-O-di-tert-butylsilylene-2-deoxy-2-trifluoroacetamido- $\beta$ - $D$ galactopyranosyl)-( $1 \rightarrow 4)$-benzyl $\quad 2$-O-benzoyl-3-O-benzyl- $\beta$-Dglucopyranosiduronate (11): Donor $10(208 \mathrm{mg}, 0.186 \mathrm{mmol})$ and aceptor 7 (71 $\mathrm{mg}, 0.072 \mathrm{mmol})$ were coevaporated with toluene, concentrated in vacuo and dissolved in dry $\mathrm{CH}_{2} \mathrm{Cl}_{2}(3 \mathrm{~mL})$ in the presence of freshly activated $4 \AA$ molecular sieves $(225 \mathrm{mg})$. After stirring for 15 min at $0 \stackrel{\circ}{\circ}$, TMSOTf $\left(200 \mu \mathrm{L}\right.$ of a $0.19 \mathrm{M}$ solution in dry $\left.\mathrm{CH}_{2} \mathrm{Cl}_{2}\right)$ was added under an argon atmosphere. After stirring for 30 min at $0^{\circ} \mathrm{C}$ the reaction mixture was neutralized with $\mathrm{Et}_{3} \mathrm{~N}$, filtered, and concentrated to dryness. The residue was purified by column chromatography $\left(\mathrm{CH}_{2} \mathrm{Cl}_{2}\right.$ $100 \% \rightarrow \mathrm{CH}_{2} \mathrm{Cl}_{2}$-acetone $\left.80: 1\right)$ to afford $\mathbf{1 1}$ as a white foam $(75 \mathrm{mg}$, 54\%). TLC $\left(\mathrm{CH}_{2} \mathrm{Cl}_{2} \text {-acetone 80:1) Rf 0.23; [a }\right]^{20}{ }_{\mathrm{D}}+19.8^{\circ}$ (c 1.0, $\left.\mathrm{CHCl}_{3}\right)$; ${ }^{1} \mathrm{H}$-NMR $\left(400 \mathrm{MHz}, \mathrm{CDCl}_{3}\right)$ : $\delta 7.95(\mathrm{~m}, 4 \mathrm{H}, \mathrm{Ar}), 7.58(\mathrm{~m}, 2 \mathrm{H}, \mathrm{Ar}), 7.49$ $7.09(\mathrm{~m}, 24 \mathrm{H}, \mathrm{Ar}), 6.89-6.87(\mathrm{~m}, 3 \mathrm{H}, \mathrm{Ar}, \mathrm{NH}), 6.69(\mathrm{~m}, 2 \mathrm{H}, \mathrm{Ar}), 6.51$ (br d, $\left.1 \mathrm{H}, J_{2, \mathrm{NH}}=8.2 \mathrm{~Hz}, \mathrm{NH}\right), 5.47\left(\mathrm{t}, 1 \mathrm{H}, J_{1,2}=J_{2,3}=7.0 \mathrm{~Hz}, \mathrm{H}-2 \mathrm{~A}\right.$ or C), 5.39 (d, $\left.1 \mathrm{H}, \mathrm{CH}_{2}(\mathrm{Bn})\right), 5.27$ (t, $1 \mathrm{H}, J_{1,2}=J_{2,3}=7.4 \mathrm{~Hz}, \mathrm{H}-2 \mathrm{~A}$ or $\mathrm{C}$ ), 5.18-5.07 $\left(\mathrm{m}, 5 \mathrm{H}, \mathrm{H}-1 \mathrm{~A}, \mathrm{H}-1 \mathrm{C}, 3 \times \mathrm{CH}_{2}(\mathrm{Bn})\right), 4.89\left(2 \mathrm{~d}, 2 \mathrm{H}, \mathrm{CH}_{2}(\mathrm{Bn})\right), 4.69(\mathrm{~m}, 2 \mathrm{H}$, $\mathrm{H}-1 \mathrm{~B}$ or $\left.\mathrm{D}, \mathrm{CH}_{2}(\mathrm{Bn})\right)$, $4.56\left(\mathrm{~d}, 1 \mathrm{H}, \mathrm{CH}_{2}(\mathrm{Bn})\right)$, 4.47-4.44 (m, $4 \mathrm{H}, \mathrm{H}-2 \mathrm{~B}$ or $\mathrm{D}$, H-4B, H-4D, H-3D), 4.35 (t, 1H, $J_{3.4}=J_{4.5}=7.8 \mathrm{~Hz}, \mathrm{H}-4 \mathrm{~A}$ or C), 4.18-3.95 (m, $9 \mathrm{H}, \mathrm{H}-2 \mathrm{~B}$ or $\mathrm{D}, \mathrm{H}-6 \mathrm{~B}, \mathrm{H}-6 \mathrm{D}, \mathrm{H}-1 \mathrm{~B}$ or $\mathrm{D}, \mathrm{H}-5 \mathrm{~A}, \mathrm{H}-5 \mathrm{C}, \mathrm{H}-4 \mathrm{~A}$ or $\mathrm{C}$ ), 3.90 (t, $1 \mathrm{H}, \mathrm{H}-3 \mathrm{~A}$ or $\mathrm{C}), 3.83-3.76(\mathrm{~m}, 2 \mathrm{H}, \mathrm{H}-3 \mathrm{~B}, \mathrm{H}-3 \mathrm{~A}$ or $\mathrm{C}), 3.73(\mathrm{~s}, 3 \mathrm{H}, \mathrm{Me}$ (OMP)), 3.00-2.86 (2 br s, 2H, H-5B, H-5D), 2.80-2.60 (m, 4H, $\mathrm{CH}_{2}(\mathrm{Lev})$ ), 2.21 (s, 3H, $\left.\mathrm{CH}_{3}(\mathrm{Lev})\right), 1.04-0.96\left(\mathrm{~m}, 36 \mathrm{H}, \mathrm{C}\left(\mathrm{CH}_{3}\right)_{3}\right) ;{ }^{13} \mathrm{C}-\mathrm{NMR}(100 \mathrm{MHz}$, $\left.\mathrm{CDCl}_{3}\right): \delta 206.3,172.4,169.4,168.9,165.1,165.0(6 \times \mathrm{CO}), 157.5(2 \mathrm{q}$ $\mathrm{COCF}_{3}$ ), 155.5-114.3 (Ar), 117.2 (2q, $\left.\mathrm{COCF}_{3}\right), 101.3,101.2(\mathrm{C}-1 \mathrm{~B}, \mathrm{C}-1 \mathrm{D})$ 100.4, 100.0 (C-1A, C-1C), 79.7, 79.6 (C-3A, C-3C), 79.3, 78.6 (C-4A, C4C), 76.6 (C-3B), 74.6, 74.55, 74.48, 74.2 (C-5A, C-5C, $\left.\mathrm{CH}_{2}(\mathrm{Bn})\right), 73.4$, $73.1,72.2,72.1,71.9,71.7,69.3$ (C-5B, C-5D, C-2A, C-2C, C-4B, C-4D, C-3D), 67.9, $67.5\left(\mathrm{CH}_{2}(\mathrm{Bn})\right), 66.6,66.4$ (C-6B, C-6D), 55.6 (Me (OMP)), 52.1, 50.0 (C-2B, C-2D), $37.8\left(\mathrm{CH}_{2}(\mathrm{Lev})\right), 29.7\left(\mathrm{CH}_{3}(\mathrm{Lev})\right), 28.2$ $\left(\mathrm{CH}_{2}(\mathrm{Lev})\right)$, 27.6-27.2 $\left(\mathrm{C}\left(\mathrm{CH}_{3}\right)_{3}\right)$, 23.3-20.4 $\left(\mathrm{C}\left(\mathrm{CH}_{3}\right)_{3}\right)$; ESI MS: $\mathrm{m} / \mathrm{z}$ : calcd for $\mathrm{C}_{98} \mathrm{H}_{114} \mathrm{~F}_{6} \mathrm{~N}_{2} \mathrm{O}_{28} \mathrm{Si}_{2} \mathrm{Na}: 1960.7$; found: $1960.7[\mathrm{M}+\mathrm{Na}]^{+}$.
\end{abstract}

\begin{abstract}
4-Methoxyphenyl $\quad$ O-(2-deoxy-3-O-levulinoyl-2-trifluoroacetamido- $\beta$ D-galactopyranosyl)-(1 $\rightarrow 4)$-O-(benzyl 2-O-benzoyl-3-O-benzyl- $\beta$-Dglucopyranosyluronate)-(1 $\rightarrow 3)$-O-(2-deoxy-2-trifluoroacetamido- $\beta$-Dgalactopyranosyl)-(1 $\rightarrow 4)$-benzyl 2-O-benzoyl-3-O-benzyl- $\beta$-Dglucopyranosiduronate (12): An excess of $(\mathrm{HF})_{n} \cdot \operatorname{Py}(110 \mu \mathrm{L}, 4.2 \mathrm{mmol})$ was added at $0^{\circ} \mathrm{C}$ under an argon atmosphere to a solution of $11(41 \mathrm{mg}$, $0.021 \mathrm{mmol})$ in dry THF $(2.0 \mathrm{~mL})$. After $20 \mathrm{~h}$ at $0^{\circ} \mathrm{C}$ the mixture was diluted with $\mathrm{CH}_{2} \mathrm{Cl}_{2}$ and washed with $\mathrm{H}_{2} \mathrm{O}$ and saturated $\mathrm{NaHCO}_{3}$ solution until neutral $\mathrm{pH}$. The organic layers were dried $\left(\mathrm{MgSO}_{4}\right)$, filtered and concentrated in vacuo to give $\mathbf{1 2}$ ( $35 \mathrm{mg}$, quantitative) as a white amorphous solid. TLC $\left(\mathrm{CH}_{2} \mathrm{Cl}_{2}-\mathrm{MeOH} 20: 1\right) \mathrm{Rf} 0.43 ;{ }^{1} \mathrm{H}-\mathrm{NMR}(400 \mathrm{MHz}$, $\mathrm{CDCl}_{3} / \mathrm{CD}_{3} \mathrm{OD}$ 5:1): $\delta 7.92(\mathrm{~m}, 4 \mathrm{H}, \mathrm{Ar}), 7.55(\mathrm{~m}, 2 \mathrm{H}, \mathrm{Ar}), 7.43-7.00(\mathrm{~m}$, $24 \mathrm{H}, \mathrm{Ar}), 6.78(\mathrm{~m}, 2 \mathrm{H}, \mathrm{Ar}), 6.61(\mathrm{~m}, 2 \mathrm{H}, \mathrm{Ar}), 5.28(\mathrm{~m}, 2 \mathrm{H}, \mathrm{H}-2 \mathrm{~A}$ or $\mathrm{C}$, $\left.\mathrm{CH}_{2}(\mathrm{Bn})\right)$, $5.19\left(\mathrm{~d}, 1 \mathrm{H}, \mathrm{CH}_{2}(\mathrm{Bn})\right), 5.12-5.07\left(\mathrm{~m}, 2 \mathrm{H}, \mathrm{H}-2 \mathrm{~A}\right.$ or $\left.\mathrm{C}, \mathrm{CH}_{2}(\mathrm{Bn})\right)$, 5.00-4.96 (m, $2 \mathrm{H}, \mathrm{CH}_{2}(\mathrm{Bn}), \mathrm{H}-1 \mathrm{~A}$ or $\left.\mathrm{C}\right)$, 4.92-4.85 (2d, $\left.2 \mathrm{H}, \mathrm{CH}_{2}(\mathrm{Bn})\right)$, $4.77\left(\mathrm{~d}, 1 \mathrm{H}, J_{1,2}=7.4 \mathrm{~Hz}, \mathrm{H}-1 \mathrm{~A}\right.$ or C), $4.70\left(\mathrm{dd}, 1 \mathrm{H}, J_{2,3}=11.2 \mathrm{~Hz}, J_{3,4}=\right.$ 3.0 Hz, H-3D), 4.51 (m, 4H, CH $2(B n), H-1 B, H-1 D), 4.32-4.17(m, 3 \mathrm{H}, \mathrm{H}-$ 2D, H-4A, H-4C), 4.03-3.93 (m, 4H, H-5A, H-5C, H-4D, H-2B), 3.83-3.66 (m, 9H, H-3B, H-3A, H-3C, H-4B, $1 \times$ H-6B, $1 \times \mathrm{H}-6 \mathrm{D}$, Me (OMP)), 3.48 (dd, 1H, H-6D), 3.33 (dd, 1H, H-6B), 3.30-3.24 (m, 2H, H-5B, H-5D), 2.76-2.48 (m, 4H, $\left.\mathrm{CH}_{2}(\mathrm{Lev})\right), 2.14$ (s, 3H, $\left.\mathrm{CH}_{3}(\mathrm{Lev})\right) ;{ }^{13} \mathrm{C}-\mathrm{NMR}(100 \mathrm{MHz}$, $\mathrm{CDCl}_{3} / \mathrm{CD}_{3} \mathrm{OD} 5: 1$, selected data from HSQC experiment): $\delta 104.7,104.5$ (C-1A, C-1C), 103.7 (C-1B, C-1D), 83.8 (C-3A, C-3C), 82.8 (C-3B), 79.8 (C-4A, C-4C, $2 \times \mathrm{CH}_{2}(\mathrm{Bn})$ ), 79.6 (C-5B, C-5D), 78.0, 77.8 (C-5A, C-5C), 76.9 (C-3D), 76.2, 76.1 (C-2A, C-2C), 71.9, $71.4\left(2 \times \mathrm{CH}_{2}(\mathrm{Bn})\right), 71.9$ (C-
\end{abstract}

4B), 69.7 (C-4D), 66.0, 65.5 (C-6B, C-6D), 59.4 (Me (OMP)), 55.9, 54.7 (C-2B, C-2D); HR MS: $\mathrm{m} / \mathrm{z}$ : calcd for $\mathrm{C}_{82} \mathrm{H}_{82} \mathrm{~F}_{6} \mathrm{~N}_{2} \mathrm{O}_{28} \mathrm{Na}$ : 1679.4850 ; found: $1679.4838[\mathrm{M}+\mathrm{Na}]^{+}$.

4-Methoxyphenyl O-(2-acetamido-2-deoxy-4,6-di-O-sulfo- $\beta$-Dgalactopyranosyl)-(1 $\rightarrow 4)$ - $O$-( $\beta$-D-glucopyranosyluronic acid)-( $1 \rightarrow 3$ )O-(2-acetamido-2-deoxy-4,6-di-O-sulfo- $\beta$-D-galactopyranosyl)-(1 $\rightarrow 4)$ $\beta$-D-glucopyranosiduronic acid (15) Compound 12 (14 mg, $8.4 \mu \mathrm{mol})$ and sulfur trioxide-trimethylamine complex $(47 \mathrm{mg}, 0.34 \mathrm{mmol}$ ) were dissolved in dry DMF $(1.5 \mathrm{~mL})$ and heated at $100^{\circ} \mathrm{C}$ for 30 min using microwave radiation ( $20 \mathrm{~W}$ average power). The reaction vessel was cooled and $\mathrm{Et}_{3} \mathrm{~N}(300 \mu \mathrm{L}), \mathrm{MeOH}(1 \mathrm{~mL})$ and $\mathrm{CH}_{2} \mathrm{Cl}_{2}(1 \mathrm{~mL})$ were added. The solution was layered on the top of a Sephadex LH 20 chromatography column which was eluted with $\mathrm{CH}_{2} \mathrm{Cl}_{2}-\mathrm{MeOH}$ (1:1) to obtain 13 as triethylammonium salt (20 mg, quantitative). TLC (EtOAc/pyridine/ $\mathrm{H}_{2} \mathrm{O} / \mathrm{AcOH}$ 12:5:3:1) Rf $0.28 ;{ }^{1} \mathrm{H}-\mathrm{NMR}$ (400 MHz, $\left.\mathrm{CD}_{3} \mathrm{OD}\right): \delta 7.98(\mathrm{~m}, 4 \mathrm{H}, \mathrm{Ar}), 7.63(\mathrm{~m}, 2 \mathrm{H}, \mathrm{Ar}), 7.51-7.07(\mathrm{~m}, 24 \mathrm{H}, \mathrm{Ar})$ $6.84(\mathrm{~m}, 2 \mathrm{H}, \mathrm{Ar}), 6.72(\mathrm{~m}, 2 \mathrm{H}, \mathrm{Ar}), 5.45\left(\mathrm{~d}, 1 \mathrm{H}, \mathrm{CH}_{2}(\mathrm{Bn})\right), 5.37-5.24(\mathrm{~m}$, $\left.5 \mathrm{H}, \mathrm{H}-2 \mathrm{~A}, \mathrm{H}-2 \mathrm{C}, \mathrm{H}-1 \mathrm{~A}, \mathrm{CH}_{2}(\mathrm{Bn})\right), 5.11\left(\mathrm{~d}, 1 \mathrm{H}, \mathrm{CH}_{2}(\mathrm{Bn})\right)$, 5.04-4.94 (m, $\left.4 \mathrm{H}, \mathrm{CH}_{2}(\mathrm{Bn}), \mathrm{H}-1 \mathrm{C}, \mathrm{H}-3 \mathrm{D}\right), 4.87-4.81$ (m, 3H, H-4D, H-4B, H-1D), 4.72 (d, $\left.1 \mathrm{H}, J_{1,2}=8.1 \mathrm{~Hz}, \mathrm{H}-1 \mathrm{~B}\right), 4.61\left(\mathrm{~d}, 1 \mathrm{H}, \mathrm{CH}_{2}(\mathrm{Bn})\right), 4.55-4.22(\mathrm{~m}, 8 \mathrm{H}$, $\left.\mathrm{CH}_{2}(\mathrm{Bn}), 3 \times \mathrm{H}-6 \mathrm{~B} / \mathrm{D}, \mathrm{H}-4 \mathrm{~A}, \mathrm{H}-4 \mathrm{C}, \mathrm{H}-2 \mathrm{D}, \mathrm{H}-5 \mathrm{~A}\right), 4.18-4.08$ (m, 3H, H-5C, $\mathrm{H}-2 \mathrm{~B}, \mathrm{H}-6 \mathrm{~B}$ or $\mathrm{D}), 4.03-3.96(\mathrm{~m}, 3 \mathrm{H}, \mathrm{H}-3 \mathrm{~B}, \mathrm{H}-3 \mathrm{~A}, \mathrm{H}-5 \mathrm{~B}$ or $\mathrm{D}), 3.89$ (t, $1 \mathrm{H}$, $\left.J_{2,3}=J_{3,4}=8.6 \mathrm{~Hz}, \mathrm{H}-3 \mathrm{C}\right), 3.81(\mathrm{~m}, 1 \mathrm{H}, \mathrm{H}-5 \mathrm{~B}$ or $\mathrm{D}), 3.72(\mathrm{~s}, 3 \mathrm{H}, \mathrm{Me}$ (OMP)), 3.17 (q, 24H, Et ${ }_{3} \mathrm{NH}^{+}$), 2.84-2.59 (m, 4H, $\left.\mathrm{CH}_{2}(\mathrm{Lev})\right), 2.16(\mathrm{~s}, 3 \mathrm{H}$, $\left.\mathrm{CH}_{3}(\mathrm{Lev})\right), 1.28$ (t, $\left.36 \mathrm{H}, \mathrm{Et}_{3} \mathrm{NH}^{+}\right) ;{ }^{13} \mathrm{C}-\mathrm{NMR}\left(100 \mathrm{MHz}, \mathrm{CD}_{3} \mathrm{OD}\right.$, selected data from HSQC experiment): $\delta 100.9(\mathrm{C}-1 \mathrm{C}), 99.6$ (C-1A), $99.4(\mathrm{C}-1 \mathrm{~B})$, 99.3 (C-1D), 79.7 (C-3C), 79.2 (C-3A), 76.3 (C-4A, C-4C), 75.2 (C-4B), 74.9 (C-3B or C-5B or D), $74.4\left(\mathrm{CH}_{2}(\mathrm{Bn})\right), 74.3(\mathrm{C}-5 \mathrm{C}), 74.2(\mathrm{C}-5 \mathrm{~A}), 73.7$ $\left(\mathrm{CH}_{2}(\mathrm{Bn})\right), 73.2$ (C-5B or D), 72.9 (C-3B or C-5B or D), 72.5 (C-2A, C-2C), 71.1 (C-4D), 70.3 (C-3D), 67.5, 67.0 (C-6B, C-6D), 67.4, $66.7\left(\mathrm{CH}_{2}(\mathrm{Bn})\right)$, 54.5 (Me (OMP)), 52.1 (C-2B), 50.5 (C-2D); ESI MS: m/z: calcd for $\mathrm{C}_{82} \mathrm{H}_{79} \mathrm{~F}_{6} \mathrm{~N}_{2} \mathrm{O}_{40} \mathrm{NaKS}_{4}:$ 2035.3; found: $2035.3[\mathrm{M}+\mathrm{Na}+\mathrm{K}+\mathrm{H}]$

$\mathrm{H}_{2} \mathrm{O}_{2}(30 \%, 0.33 \mathrm{~mL})$ and an aqueous solution of $\mathrm{LiOH}(0.7 \mathrm{~m}, 0.20 \mathrm{~mL})$ were added at $0^{\circ} \mathrm{C}$ to a solution of $13(20 \mathrm{mg}, 8.4 \mu \mathrm{mol})$ in THF $(0.9 \mathrm{~mL})$. After stirring for $20 \mathrm{~h}$ at room temperature, $\mathrm{MeOH}(1.75 \mathrm{~mL}), \mathrm{H}_{2} \mathrm{O}(0.5$ $\mathrm{mL}$ ) and an aqueous solution of $\mathrm{NaOH}(4 \mathrm{~m}, 0.42 \mathrm{~mL}$ ) were added. After stirring for $48 \mathrm{~h}$ at room temperature, the reaction mixture was neutralized with Amberlite IR-120 $\left(\mathrm{H}^{+}\right)$resin, filtered, and concentrated to give the desired diamine intermediate. Triethylamine $(32 \mu \mathrm{L}, 0.23 \mathrm{mmol})$ and acetic anhydride $(32 \mu \mathrm{L}, 0.34 \mathrm{mmol})$ were added to a cooled $\left(0^{\circ} \mathrm{C}\right)$ solution of this diamine derivative in dry $\mathrm{MeOH}(2.0 \mathrm{~mL})$. After stirring for $2 \mathrm{~h}$ at r.t., $\mathrm{Et}_{3} \mathrm{~N}(300 \mu \mathrm{L})$ was added and the mixture was concentrated to dryness. The residue was purified by silica gel column chromatography (EtOAc-MeOH- $\mathrm{H}_{2} \mathrm{O}$ 16:5:3 $+1 \% \mathrm{Et}_{3} \mathrm{~N}$ ) to give 14. This compound was then dissolved in $\mathrm{H}_{2} \mathrm{O}(2 \mathrm{~mL})$ and Amberlite IR-120 $\mathrm{H}^{+}$resin was added $(\mathrm{pH}=3.0)$. The mixture was immediately filtered, treated with $0.04 \mathrm{M}$ $\mathrm{NaOH}(\mathrm{pH}=7.1)$ and lyophilized. The white solid was finally eluted from a column of Dowex $50 \mathrm{WX} 4-\mathrm{Na}^{+}\left(\mathrm{H}_{2} \mathrm{O}-\mathrm{MeOH}\right.$ 9:1) to obtain 14 as sodium salt $(8 \mathrm{mg}, 62 \%)$ after lyophilization. TLC (EtOAc/pyridine $/ \mathrm{H}_{2} \mathrm{O} / \mathrm{AcOH}$ 6:5:3:1) Rf 0.27; ${ }^{1} \mathrm{H}-\mathrm{NMR}\left(400 \mathrm{MHz}, \mathrm{D}_{2} \mathrm{O}\right): \delta 7.54-7.29$ (m, 10H, Ar), 7.04 (m, 2H, Ar), $6.91(\mathrm{~m}, 2 \mathrm{H}, \mathrm{Ar}), 4.95-4.93\left(\mathrm{~m}, 2 \mathrm{H}, \mathrm{CH}_{2}(\mathrm{Bn}), \mathrm{H}-1 \mathrm{~A}\right), 4.87(\mathrm{~d}$, $\left.1 \mathrm{H}, \mathrm{CH}_{2}(\mathrm{Bn})\right)$, 4.77-4.67 (m, 4H, H-4B, H-4D, $\left.\mathrm{CH}_{2}(\mathrm{Bn})\right), 4.59\left(\mathrm{~d}, 1 \mathrm{H}, J_{1,2}\right.$ $=8.2 \mathrm{~Hz}, \mathrm{H}-1 \mathrm{~B}), 4.54\left(\mathrm{~d}, 1 \mathrm{H}, J_{1,2}=8.3 \mathrm{~Hz}, \mathrm{H}-1 \mathrm{D}\right), 4.44\left(\mathrm{~d}, 1 \mathrm{H}, J_{1,2}=7.6\right.$ $\mathrm{Hz}, \mathrm{H}-1 \mathrm{C}$ ), 4.19 (dd, $1 \mathrm{H}, J_{5,6 \mathrm{a}}=3.6 \mathrm{~Hz}, \mathrm{~J}_{6 \mathrm{a}, 6 \mathrm{~b}}=10.8 \mathrm{~Hz}, \mathrm{H}-6 \mathrm{~B}$ or D), $4.15-$ $3.88(\mathrm{~m}, 10 \mathrm{H}, 3 \times \mathrm{H}-6 \mathrm{~B} / \mathrm{D}, \mathrm{H}-4 \mathrm{~A}, \mathrm{H}-2 \mathrm{~B}, \mathrm{H}-4 \mathrm{C}, \mathrm{H}-2 \mathrm{D}, \mathrm{H}-3 \mathrm{~B}, \mathrm{H}-5 \mathrm{~B}, \mathrm{H}-5 \mathrm{D})$, 3.82-3.76 (m, 2H, H-5A, H-3D), 3.75 (s, 3H, Me (OMP)), 3.67 (m, 2H, H$2 \mathrm{~A}, \mathrm{H}-3 \mathrm{~A}), 3.62\left(\mathrm{~d}, 1 \mathrm{H}, \mathrm{J}_{4,5}=9.7 \mathrm{~Hz}, \mathrm{H}-5 \mathrm{C}\right), 3.55\left(\mathrm{t}, 1 \mathrm{H}, \mathrm{J}_{2,3}=J_{3,4}=9.2\right.$ $\mathrm{Hz}, \mathrm{H}-3 \mathrm{C}), 3.48$ (t, $1 \mathrm{H}, \mathrm{H}-2 \mathrm{C}), 2.01-2.00(2 \mathrm{~s}, 6 \mathrm{H}, \mathrm{NHAc}) ;{ }^{13} \mathrm{C}-\mathrm{NMR}(100$ $\mathrm{MHz}, \mathrm{D}_{2} \mathrm{O}$, selected data from HSQC experiment): $\delta$ 128.9-114.8 (Ar), 103.6 (C-1C), 101.1 (C-1A), 99.9 (C-1D), 99.6 (C-1B), 80.9 (C-3A, C-3C), 76.7 (C-5A), 76.6 (C-4A), 76.5-75.7 (C-4C, C-4B, C-3B, C-5C), 75.4 (C4D), 73.8, $73.6\left(\mathrm{CH}_{2}(\mathrm{Bn})\right), 71.9$ (C-5B, C-5D), $71.7(\mathrm{C}-2 \mathrm{~A}), 71.3(\mathrm{C}-2 \mathrm{C})$, 
70.3 (C-3D), 67.5, 66.6 (C-6B, C-6D), 55.6 (Me (OMP)), 52.5 (C-2D), 51.3 (C-2B), 22.4 (NHAc); ESI MS: $\mathrm{m} / z$ : calcd for $\mathrm{C}_{49} \mathrm{H}_{57} \mathrm{~N}_{2} \mathrm{O}_{36} \mathrm{Na}_{3} \mathrm{KS}_{4}$ : 1485.1 ; found: $1484.8[\mathrm{M}+3 \mathrm{Na}+\mathrm{K}+\mathrm{H}]$.

A solution of 14 (4.2 mg, $2.8 \mu \mathrm{mol}$, sodium salt) in $\mathrm{H}_{2} \mathrm{O} / \mathrm{MeOH}$ (3.6 $\mathrm{mL} / 0.4 \mathrm{~mL}$ ) was hydrogenated in the presence of $20 \% \mathrm{Pd}(\mathrm{OH})_{2} / \mathrm{C}(9 \mathrm{mg})$. After $24 \mathrm{~h}$, the suspension was filtered over celite, concentrated, and lyophilized to give 15 as a white amorphous solid $(3.4 \mathrm{mg}$, sodium salt, 92\%). ${ }^{1} \mathrm{H}-\mathrm{NMR}\left(400 \mathrm{MHz}, \mathrm{D}_{2} \mathrm{O}\right): \delta 7.03(\mathrm{~m}, 2 \mathrm{H}, \mathrm{Ar}), 6.91(\mathrm{~m}, 2 \mathrm{H}, \mathrm{Ar})$, $4.95\left(\mathrm{~d}, 1 \mathrm{H}, J_{1,2}=7.9 \mathrm{~Hz}, \mathrm{H}-1 \mathrm{~A}\right), 4.73\left(\mathrm{~d}, 1 \mathrm{H}, J_{3,4}=1.9 \mathrm{~Hz}, \mathrm{H}-4 \mathrm{~B}\right), 4.66(\mathrm{~d}$ $\left.1 \mathrm{H}, J_{3,4}=2.5 \mathrm{~Hz}, \mathrm{H}-4 \mathrm{D}\right), 4.56\left(\mathrm{~d}, 1 \mathrm{H}, J_{1,2}=7.9 \mathrm{~Hz}, \mathrm{H}-1 \mathrm{~B}\right), 4.52(\mathrm{~d}, 1 \mathrm{H}$, $\left.J_{1,2}=7.6 \mathrm{~Hz}, \mathrm{H}-1 \mathrm{D}\right), 4.41\left(\mathrm{~d}, 1 \mathrm{H}, J_{1,2}=7.9 \mathrm{~Hz}, \mathrm{H}-1 \mathrm{C}\right), 4.26-4.14(\mathrm{~m}, 4 \mathrm{H}$, $\mathrm{H}-6 \mathrm{~B}, \mathrm{H}-6 \mathrm{D}$ ), 4.08-3.99 (m, 4H, H-5B, H-5D, H-2B, H-3B), 3.87-3.76 (m, 4H, H-2D, H-3D, H-4A, H-5A), 3.74 (s, 3H, Me (OMP)), 3.72-3.64 (m, 2H, $\mathrm{H}-4 \mathrm{C}, \mathrm{H}-3 \mathrm{~A}), 3.61-3.50(\mathrm{~m}, 3 \mathrm{H}, \mathrm{H}-5 \mathrm{C}, \mathrm{H}-2 \mathrm{~A}, \mathrm{H}-3 \mathrm{C}), 3.32(\mathrm{t}, 1 \mathrm{H}, \mathrm{H}-2 \mathrm{C})$, 1.98-1.96 (2s, 6H, NHAc); ${ }^{13} \mathrm{C}-\mathrm{NMR}\left(100 \mathrm{MHz}, \mathrm{D}_{2} \mathrm{O}\right.$, selected data from HSQC experiment): $\delta$ 117.9-114.6 (Ar), 103.6 (C-1C), 101.3 (C-1B, C1D), 100.8 (C-1A), 81.6 (C-4A, C-4C), 76.3 (C-5C), 76.1 (C-5A), 75.7 (C 4B), 75.3 (C-4D), 75.0 (C-3B), 73.7 (C-3A), 73.4 (C-3C), 72.2 (C-5B, C5D), 72.0 (C-2A), 71.9 (C-2C), 69.9 (C-3D), 67.5 (C-6B, C-6D), 55.6 (Me (OMP)), 52.2 (C-2D), 51.3 (C-2B), 22.2 (NHAc); ESI MS: m/z: calcd for $\mathrm{C}_{35} \mathrm{H}_{44} \mathrm{~N}_{2} \mathrm{O}_{36} \mathrm{Na}_{4} \mathrm{~S}_{4}: 644.0$; found: $643.8[\mathrm{M}+4 \mathrm{Na}]^{2-}$.

\section{Fluorescence polarization assays}

Fluorescence polarization measurements were performed in 384-well microplates (black polystyrene, non-treated, Corning). The fluorescence polarization was recorded using a TRIAD multimode microplate reader (from Dynex), with excitation and emission wavelengths of 485 and 535 $\mathrm{nm}$, respectively. The fluorescent probe (a fluorescein labelled heparinlike hexasaccharide previously prepared in our lab ${ }^{[12]}$ ) was dissolved in PBS buffer (10 mM, pH 7.4). Recombinant human midkine (Peprotech) was dissolved in PBS buffer $(10 \mathrm{mM}, \mathrm{pH} 7.4)$ containing $1 \%$ BSA. Synthetic oligosaccharides $\mathbf{1 4 - 2 7}$ were dissolved in PBS buffer $(10 \mathrm{mM}$, $\mathrm{pH}$ 7.4).

For direct binding assay between the fluorescent probe and midkine, 15 $\mu \mathrm{L}$ of a $20 \mathrm{nM}$ probe solution and $15 \mu \mathrm{L}$ of a series of midkine solutions, ranging from $1.5 \mu \mathrm{M}$ to $24 \mathrm{nM}$, were transferred to the microplate wells. The final sample volume in each well was $30 \mu \mathrm{L}$. All samples were performed in replicates of three. The microplate was shaked in the dark for $5 \mathrm{~min}$, before reading. Blank wells contained $15 \mu \mathrm{L}$ of midkine solution $(1.5 \mu \mathrm{M})$ and $15 \mu \mathrm{L}$ of PBS buffer and their measurements were substracted from all values. Wells containing $15 \mu \mathrm{L}$ of the fluorescent probe solution $(20 \mathrm{nM})$ and $15 \mu \mathrm{L}$ of PBS buffer plus $1 \%$ BSA gave the background polarization of the probe solution, in the absence of protein. The change in the fluorescence polarization $(\Delta \mathrm{P})$ was calculated by subtracting the background polarization of probe from the polarization value of the sample solutions. The $\Delta P$ values were plotted against midkine concentrations and the obtained binding curve was fitted to the equation for a one-site binding model $y=\Delta P \max x / K_{D}+x$ where $\Delta P_{\max }$ is the maximum value approached with increasing concentrations of midkine and $K_{D}$ is the dissociation constant of the probe-midkine interaction.

For the initial screening assays at a fixed concentration of inhibitor, $10 \mu \mathrm{L}$ of a $40 \mathrm{nM}$ probe solution and $20 \mu \mathrm{L}$ of a $94 \mathrm{nM}$ midkine solution were mixed with $10 \mu \mathrm{L}$ of a $100 \mu \mathrm{M}$ inhibitor solution. The total sample volume in each well was $40 \mu \mathrm{L}$ and the final buffer composition was PBS $+0.5 \%$ BSA. The final concentrations of inhibitor, fluorescent probe and midkine in each well were $25 \mu \mathrm{M}, 10 \mathrm{nM}$ and $47 \mathrm{nM}$, respectively. After stirring for $5 \mathrm{~min}$ in the dark, fluorescence polarization was recorded. Two control samples were included in the study. The first one only contained fluorescent probe and afforded the expected value for $100 \%$ inhibition; the second one contained midkine and probe, in the absence of inhibitor, and gave the polarization value corresponding to $0 \%$ inhibition. Blank wells contained $20 \mu \mathrm{L}$ of midkine solution $(94 \mathrm{nM})$ and $20 \mu \mathrm{L}$ of PBS buffer and their measurements were subtracted from all values. All samples were performed in replicates of three.

For the determination of the $\mathrm{IC}_{50}$ values, we recorded the fluorescence polarization from wells containing $20 \mu \mathrm{L}$ of a $94 \mathrm{nM}$ midkine solution and $10 \mu \mathrm{L}$ of a $40 \mathrm{nM}$ probe solution in the presence of $10 \mu \mathrm{L}$ of inhibitor solution, with concentrations ranging from $100 \mu \mathrm{M}$ to $100 \mathrm{nM}$. The total sample volume in each well was $40 \mu \mathrm{L}$ and the final buffer composition was PBS $+0.5 \%$ BSA. The final concentrations of fluorescent probe and midkine in each well were $10 \mathrm{nM}$ and $47 \mathrm{nM}$, respectively, while the final inhibitor concentration ranged from $25 \mu \mathrm{M}$ to $25 \mathrm{nM}$. The average polarization values of three replicates were plotted against the logarithm of inhibitor concentration. The curve was fitted to the equation for a onesite competition: $y=A_{2}+\left(A_{1}-A_{2}\right) /\left[1+10^{\wedge}\left(x-\log \mid C_{50}\right)\right]$ where $A_{1}$ and $A_{2}$ are respectively, the maximal and minimal values of polarization, and $I_{50}$ is the concentration that results in $50 \%$ inhibition.

NMR Spectroscopy: NMR experiments were recorded in Bruker spectrometers of 500 and $600 \mathrm{MHz}$ (Bruker Avance 500, and Bruker 600 Avance III) Fitted with inverse triple resonance probes. Samples for structural analysis were prepared in $\mathrm{D}_{2} \mathrm{O} 100 \%$ at concentrations ca. $1 \mathrm{mM}$, and using low temperature (between 280 and $283 \mathrm{~K}$ in order to increase the population of the most stable conformation, variations were imposed by the overlapping with the residual water signal). Experiments were recorded using the gradient selected or enhanced pulse programs from the manufacturer pulse sequences library. COSY-DQF, TOSCY, and NOESY were recorded using States - TTPI detection schemes in F1 and echo-antiecho with sensitivity improvement for HSQC experiments. 1D selective experiments have been acquired using 1D-DPFGSE sequences for selection. ${ }^{[27]}$

Experimental distances have been calculated using the ISPA approximation, obtaining the initial growing rates of the dipolar rate constant by fitting the growing curve of the NOE versus the mixing time to a mono exponential equation. ${ }^{[21,28]}$

STD-NMR experiments have been performed and STD amplification factors $\left(\mathrm{STD}-\mathrm{AF}_{0}\right)$ were calculated from the STD initial slopes. To do so, the evolution of the STD-AF with the saturation time ( $\left.t_{\text {sat }}\right)$ was fitted to the equation $\operatorname{STD}-A F(t)=\mathbf{a}(1-\exp (-\mathbf{b} t))$, where the parameter a represents the asymptotic maximum of the STD build-up curve $\left(S T D_{\max }\right), \mathbf{b}$ is a rate constant related to the relaxation properties of a given proton that measures the speed of the STD build-up $\left(k_{\text {sat }}\right)$, and $t$ is the saturation time $\left(t_{\text {sat }}\right)$. Thus, the STD-AFo values were obtained as the product of the ab coefficients. ${ }^{[26 b]}$

Molecular Dynamics: In all cases, the starting geometries were generated from the available data ${ }^{[29]}$ deposited in the Protein Data Bank (pdb code $1 \mathrm{hpn}$ ) and modified accordingly. The topologies were built employing the residues and the set of partial charges published by Perez et $a l^{[30]}$ (the latter developed under the framework of the set of parameters for carbohydrates $\mathrm{PIM}^{[31]}$ ) and the force fields parm9 $1^{[32]}$ of Amber 12 and glycam $06^{[33]}$ together with the set of Altona parameters for sulfates ${ }^{[34]}$. In the case of IdoA containing tetrasaccharides, two independent starting geometries were built, one with the IdoA residue in the chair ${ }^{1} \mathrm{C}_{4}$ conformation and one with the IdoA in the ${ }^{2} \mathrm{~S}_{0}$ skew boat geometry. Each of these models was immersed in a $10 \AA$-sided cube of pre-equilibrated TIP3P water molecules. 
To equilibrate the system we have followed a protocol consisting of 10 steps. Firstly, only the water molecules and ions were minimized. Then the system is heated to $300 \mathrm{~K}$ by a 3 ps MD simulation, allowing only water molecules and ions to move. Next, the whole system is minimized by four consecutive steps imposing positional restraints on the solute, with a force constant decreasing step by step from 20 to $5 \mathrm{kcal} / \mathrm{mol}$. Finally, a non-restraint minimization (100 steps) is carried out.

The production dynamics simulations were accomplished at a constant temperature of $300 \mathrm{~K}$ (by applying the Berendsen coupling algorithm ${ }^{[35]}$ for the temperature scaling) and constant pressure (1 bar). The Particle Mesh Ewald Method ${ }^{[36]}$ (to introduce long-range electrostatic effects) and periodic boundary conditions were also turned on. The SHAKE algorithm for hydrogen atoms, which allows using a 2 fs time step, was also employed. Finally, a $9 \AA$ cutoff was applied for the Lennard-Jones interactions.

MD simulations have been performed with the Pmemd module of Amber 12, with explicit treatment of the 1012 hydrogen bond potential, in agreement with the parameters set for sulfates. The trajectory coordinates were saved each 0.5 ps. The overall length for the simulations was $200-500$ ns. The data processing of the trajectories were done with the ptraj module of Amber 12, except for the CremerPople puckering coordinates, which were calculated with the Carnal module of Amber 5.0.

The time-averaged restrained molecular dynamics were run following the above-commented protocol. In the production step, a single NOE-derived distance, between $\mathrm{H} 2$ and $\mathrm{H} 5$ protons of the IdoA residue (Table 2), was imposed as time-averaged constraint, applying an $\mathbf{r}^{-6}$ averaging. The equilibrium distance range was set to $r_{\exp }-0.1 \AA \leq r_{\exp } \leq r_{\exp }+0.1 \AA$. Trajectories were run at $278 \mathrm{~K}$, with a decay constant of $800 \mathrm{ps}$ and a time step of $1 \mathrm{fs}$. The force constants $\mathbf{r}_{\mathrm{k} 2}$ and $\mathbf{r}_{\mathrm{k} 3}$ used in each case go from 25 to $45 \mathrm{kcal} \mathrm{mol}^{-1} \mathrm{~A}^{-2}$. The overall length for the simulations was 8 ns for the tar-MD simulations. The coordinates were saved each picosecond, thus, obtaining tar MD trajectories of 8000 frames each. Convergence within the equilibrium distance range was obtained in all cases. The analysis of the tar -MD trajectories has been carried out with the ptraj module of AMBER 11. ${ }^{[33 a]}$ This protocol has been previously discussed in detail by us. ${ }^{[23]}$

Docking: Docking has been performed using Induced Fit Docking (IDF) as implemented in Glide module of Maestro suite. ${ }^{[37]}$ The complexes structures were constructed using the module AutodockTools 1.5.6 from Autodock Vina. The model 3 from the NMR ensemble for midkine-A deposited in the Protein Data Bank (pdb code: 2LUT) was used as model of the protein ${ }^{[25 b]}$ and minimised structures taken from the MD-tar of the tetrasaccharides were used for the carbohydrate structures. The initial models were calculated using a centred box including the complete protein with a grid of $1 \AA$. The docking was performed considering the complete set of interactions of all the residues within $12 \AA$ or the residues described previously as potential interacting with the ligand for midkine-B. The clusters, numbered according the 2LUT sequence, were: Cluster 1: K82-R84-K105; Cluster2: Q89-K90-L92; Cluster3: R38-R47; Cluster4 K48-K50-R52; Hinge: K58-K59. Both approximations give similar results.

A $30 \AA$ sided cubic grid from the centroid of the ligand was generated. The ten lowest energy conformers of each ligand were submitted to flexible SP docking using Glide. The sampling of ring conformations was turned off. The penalization of the non-planar conformations for amide type torsions and the sampling of nitrogen inversions were turned on. A distance dependent dielectric constant of 4 was used and post-docking minimization was performed.

\section{Acknowledgements}

We thank the Spanish Ministry of Economy and Competitiveness (CTQ2012-32605), and the European Union (FEDER) for financial support.

Keywords: oligosaccharides $\cdot$ chondroitin sulfate $\cdot$ structureactivity relationships $\cdot$ carbohydrate-protein interactions $\bullet$ STDNMR

[1] a) K. Sugahara, T. Mikami, T. Uyama, S. Mizuguchi, K. Nomura and H. Kitagawa, Curr. Opin. Struct. Biol. 2003, 13, 612-620; b) R. M. Lauder, Complement. Ther. Med. 2009, 17, 56-62.

[2] C. I. Gama, S. E. Tully, N. Sotogaku, P. M. Clark, M. Rawat, N. Vaidehi, W. A. Goddard, A. Nishi and L. C. Hsieh-Wilson, Nat. Chem. Biol. 2006, 2, 467-473.

[3] a) C. J. Rogers, P. M. Clark, S. E. Tully, R. Abrol, K. C. Garcia, W. A. Goddard, III and L. C. Hsieh-Wilson, Proc. Natl. Acad. Sci. U. S. A. 2011, 108, 9747-9752; b) H. Kawashima, K. Atarashi, M. Hirose, J. Hirose, S. Yamada, K. Sugahara and M. Miyasaka, J. Biol. Chem. 2002, 277, 12921-12930

[4] a) T. Muramatsu, Curr. Pharm. Des. 2011, 17, 410-423; b) K. Kadomatsu, S. Kishida and S. Tsubota, J. Biochem. 2013, 153, 511 521.

[5] T. Matsui, K. Ichihara-Tanaka, C. Lan, H. Muramatsu, T. Kondou, C. Hirose, S. Sakuma and T. Muramatsu, Int. Arch. Med. 2010, 3, 12-12.

[6] S. S. Deepa, Y. Umehara, S. Higashiyama, N. Itoh and K. Sugahara, J. Biol. Chem. 2002, 277, 43707-43716.

[7] a) J. Tamura, H. Tanaka, A. Nakamura and N. Takeda, Tetrahedron Lett. 2013, 54, 3940-3943; b) S. E. Tully, R. Mabon, C. I. Gama, S. M. Tsai, X. W. Liu and L. C. Hsieh-Wilson, J. Am. Chem. Soc. 2004, 126, 7736-7737; c) E. Bedini and M. Parrilli, Carbohydr. Res. 2012, 356, 7585; d) C. Lopin and J. C. Jacquinet, Angew. Chem. Int. Ed. 2006, 45 2574-2578; e) A. Vibert, C. Lopin-Bon and J. C. Jacquinet, Chem. Eur. J. 2009, 15, 9561-9578; f) J. C. Jacquinet, C. Lopin-Bon and A. Vibert, Chem. Eur. J. 2009, 15, 9579-9595; g) J. Tamura, Y. Nakada, K. Taniguchi and M. Yamane, Carbohydr. Res. 2008, 343, 39-47; h) S. Eller, M. Collot, J. Yin, H. S. Hahm and P. H. Seeberger, Angew. Chem. Int. Ed. 2013, 52, 5858-5861; i) J. C. Jacquinet and C. Lopin-Bon, Carbohydr. Res. 2015, 402, 35-43; j) K. Miyachi, M. Wakao and Y. Suda, Bioorg. Med. Chem. Lett. 2015, 25, 1552-1555.

[8] a) S.-G. Lee, J. M. Brown, C. J. Rogers, J. B. Matson, C. Krishnamurthy, M. Rawat and L. C. Hsieh-Wilson, Chem. Sci. 2010, 1, 322-325; b) G. Despras, C. Bernard, A. Perrot, L. Cattiaux, A. Prochiantz, H. Lortat-Jacob and J.-M. Mallet, Chem. Eur. J. 2013, 19, 530-539; c) M. Rawat, C. I. Gama, J. B. Matson and L. C. Hsieh-Wilson, J. Am. Chem. Soc. 2008, 130, 2959-2961; d) P. Liu, L. Chen, J. K. C. Toh, Y. L. Ang, J.-E. Jee, J. Lim, S. S. Lee and S.-G. Lee, Chem. Sci. 2015, 6, 450-456

[9] a) S. Mizumoto, S. Yamada and K. Sugahara, Curr. Opin. Struct. Biol. 2015, 34, 35-42; b) R. Ramachandra, R. B. Namburi, O. OrtegaMartinez, X. Shi, J. Zaia, S. T. Dupont, M. C. Thorndyke, U. Lindahl and D. Spillmann, Glycobiology 2014, 24, 195-207.

[10] a) G. Künze, J. P. Gehrcke, M. T. Pisabarro and D. Huster, Glycobiology 2014, 24, 1036-1049; b) A. Pichert, S. A. Samsonov, S Theisgen, L. Thomas, L. Baumann, J. Schiller, A. G. Beck-Sickinger, D. Huster and M. T. Pisabarro, Glycobiology 2012, 22, 134-145.

[11] G. Macchione, S. Maza, M. M. Kayser, J. L. de Paz and P. M. Nieto, Eur. J. Org. Chem. 2014, 2014, 3868-3884.

[12] S. Maza, M. Mar Kayser, G. Macchione, J. Lopez-Prados, J. Angulo, J. L. de Paz and P. M. Nieto, Org. Biomol. Chem. 2013, 11, 3510-3525.

[13] a) A. G. Gonzalez, I. Brouard, F. Leon, J. I. Padron and J. Bermejo, Tetrahedron Lett. 2001, 42, 3187-3188; b) S.-C. Hung, X.-A. Lu, J.-C. 
Lee, M. D.-T. Chang, S.-I. Fang, T.-C. Fan, M. M. L. Zulueta and Y.-Q. Zhong, Org. Biomol. Chem. 2012, 10, 760-772.

[14] A. Imamura, A. Kimura, H. Ando, H. Ishida and M. Kiso, Chem. Eur. J. 2006, 12, 8862-8870.

[15] a) S. Maza, J. L. de Paz and P. M. Nieto, Tetrahedron Lett. 2011, 52, 441-443; b) G. J. Miller, S. U. Hansen, E. Avizienyte, G. Rushton, C Cole, G. C. Jayson and J. M. Gardiner, Chem. Sci. 2013, 4, 3218-3222 c) S. U. Hansen, G. J. Miller, M. J. Cliff, G. C. Jayson and J. M. Gardiner, Chem. Sci. 2015, 6, 6158-6164.

[16] S. Maza, G. Macchione, R. Ojeda, J. Lopez-Prados, J. Angulo, J. L. de Paz and P. M. Nieto, Org. Biomol. Chem. 2012, 10, 2146-2163.

[17] a) M. Nonaka, X. Bao, F. Matsumura, S. Goetze, J. Kandasamy, A. Kononov, D. H. Broide, J. Nakayama, P. H. Seeberger and M. Fukuda, Proc. Natl. Acad. Sci. U. S. A. 2014, 111, 8173-8178; b) J. L. de Paz, C. Noti and P. H. Seeberger, J. Am. Chem. Soc. 2006, 128, 2766-2767.

[18] a) K. Sugahara and T. Mikami, Curr. Opin. Struct. Biol. 2007, 17, 536545; b) X. F. Bao, S. Nishimura, T. Mikami, S. Yamada, N. Itoh and K. Sugahara, J. Biol. Chem. 2004, 279, 9765-9776; c) C. D. Nandini, T. Mikami, M. Ohta, N. Itoh, F. Akiyama-Nambu and K. Sugahara, J. Biol. Chem. 2004, 279, 50799-50809.

[19] a) P. Sorme, B. Kahl-Knutsson, M. Huflejt, U. J. Nilsson and H. Leffler, Anal. Biochem. 2004, 334, 36-47; b) K. Kakehi, Y. Oda and M. Kinoshita, Anal. Biochem. 2001, 297, 111-116; c) J. P. Ludeman, M. Nazari-Robati, B. L. Wilkinson, C. Huang, R. J. Payne and M. J. Stone, Org. Biomol. Chem. 2015, 13, 2162-2169; d) Y.-C. He, B.-C. Yin, L. Jiang and B.-C. Ye, Chem. Commun. 2014, 50, 6236-6239; e) C. D. Rillahan, S. J. Brown, A. C. Register, H. Rosen and J. C. Paulson, Angew. Chem. Int. Ed. 2011, 50, 12534-12537; f) Z. Han, J. S. Pinkner, B. Ford, R. Obermann, W. Nolan, S. A. Wildman, D. Hobbs, T. Ellenberger, C. K. Cusumano, S. J. Hultgren and J. W. Janetka, J. Med. Chem. 2010, 53, 4779-4792; g) D. Hauck, I. Joachim, B. Frommeyer, A Varrot, B. Philipp, H. M. Moeller, A. Imberty, T. E. Exner and A. Titz, ACS Chem. Biol. 2013, 8, 1775-1784.

[20] J. Tamura, N. Tsutsumishita-Nakai, Y. Nakao, M. Kawano, S. Kato, N. Takeda, S. Nadanaka and H. Kitagawa, Bioorg. Med. Chem. Lett. 2012 22, 1371-1374.

[21] G. M. Clore and A. M. Gronenborn, J. Magn. Reson. 1985, 61, 158-164.

[22] J. C. Munoz-Garcia, J. Lopez-Prados, J. Angulo, I. Diaz-Contreras, N. Reichardt, J. L. de Paz, M. Martin-Lomas and P. M. Nieto, Chem. Eur. J. 2012, 18, 16319-16331.

[23] J. C. Munoz-Garcia, F. Corzana, J. L. de Paz, J. Angulo and P. M. Nieto, Glycobiology 2013, 23, 1220-1229.
[24] a) A. E. Torda, R. M. Scheek and W. F. Vangunsteren, Chem. Phys Lett. 1989, 157, 289-294; b) A. E. Torda, R. M. Scheek and W. F. Vangunsteren, J. Mol. Biol. 1990, 214, 223-235; c) A. P. Nanzer, W. F. Vangunsteren and A. E. Torda, J. Biomol. NMR 1995, 6, 313-320.

[25] a) W. Iwasaki, K. Nagata, H. Hatanaka, T. Inui, T. Kimura, T. Muramatsu, K. Yoshida, M. Tasumi and F. Inagaki, EMBO J. 1997, 16, 6936-6946; b) J. Lim, S. Yao, M. Graf, C. Winkler and D. Yang Biochem. J. 2013, 451, 407-415.

[26] a) M. Mayer and B. Meyer, J. Am. Chem. Soc. 2001, 123, 6108-6117 b) J. Angulo and P. M. Nieto, Eur. Biophys. J. 2011, 40, 1357-1369.

[27] K. Stott, J. Keeler, Q. N. Van and A. J. Shaka, J. Magn. Reson. 1997, $125,302-324$

[28] S. Macura, B. T. Farmer and L. R. Brown, J. Magn. Reson. 1986, 70, 493-499.

[29] B. Mulloy, M. J. Forster, C. Jones and D. B. Davies, Biochem. J. 1993 293, 849-858.

[30] S. Pérez, C. Meyer and A. Imberty, Mol. Eng. 1995, 5, 271-300.

[31] M. Clark, R. D. Cramer and N. Van Opdenbosch, J. Comput. Chem. 1989, 10, 982-1012.

[32] S. J. Weiner, P. A. Kollman, D. T. Nguyen and D. A. Case, J. Comput. Chem. 1986, 7, 230-252.

[33] a) D. A. Case, T. A. Darden, T. E. Cheatham, C. L. Simmerling, J. Wang, R. E. Duke, R. Luo, R. C. Walker, W. Zhang, K. M. Merz, B. Roberts, S. Hayik, A. Roitberg, G. Seabra, J. Swails, A. W. Goetz, I. Kolossváry, K. F. Wong, F. Paesani, J. Vanicek, R. M. Wolf, J. Liu, X Wu, S. R. Brozell, T. Steinbrecher, H. Gohlke, Q. Cai, X. Ye, J. Wang, M. J. Hsieh, G. Cui, D. R. Roe, D. H. Mathews, M. G. Seetin, R. Salomon-Ferrer, C. Sagui, V. Babin, T. Luchko, S. Gusarov, A. Kovalenko, and P. A. Kollman. Amber 12, 2012; b) R. J. Woods, R. A Dwek, C. J. Edge and B. Fraser-Reid, J. Phys. Chem. 1995, 99, 38323846

[34] C. J. M. Huige and C. Altona, J. Comput. Chem. 1995, 16, 56-79.

[35] H. J. C. Berendsen, J. P. M. Postma, W. F. Van Gunsteren, A. Dinola and J. R. Haak, J. Chem. Phys. 1984, 81, 3684-3690.

[36] a) D. M. York, T. A. Darden and L. G. Pedersen, J. Chem. Phys. 1993 99, 8345-8348; b) H. G. Petersen, J. Chem. Phys. 1995, 103, 36683679.

[37] v. Schrödinger Release 2013-2: Maestro, Schrödinger, LLC, New York, NY, 2013. in Schrödinger Release 2013-2: Maestro, version 9.5, Schrödinger, LLC, New York, NY, 2013., Vol. 2013. 


\section{Entry for the Table of Contents}

\section{FULL PAPER}

\section{Analysis of oligosaccharide-protein} interactions: we have studied the 3D solution structure of synthetic chondroitin sulfate tetrasaccharides and their interaction with midkine by using a combination of different techniques: fluorescence polarization, NMR spectroscopy, molecular dynamics and docking. Our results provide new information on the relationship between the chondroitin sulfate structure and its binding to midkine.

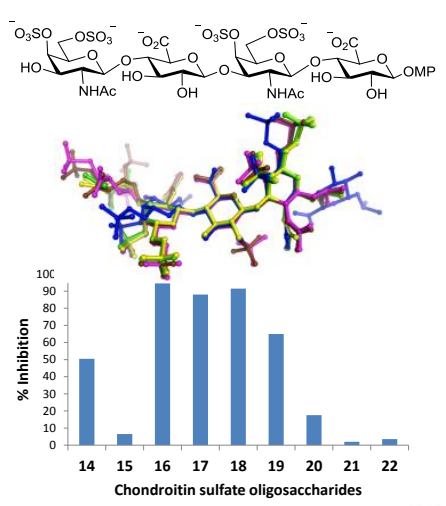

Cristina Solera, Giuseppe Macchione, Susana Maza, M. Mar Kayser, Francisco Corzana, José L. de Paz, * Pedro M. Nieto*

Page No. - Page No.

Chondroitin sulfate tetrasaccharides: synthesis, three-dimensional structure and interaction with midkine 